\title{
Article
}

\section{Attention and eye-movement control in reading: the selective reading paradigm}

Reingold, Eyal, Sheridan, Heather, Meadmore, Katie, Drieghe, Denis and Liversedge, Simon Paul

Available at https://clok.uclan.ac.uk/22348/

Reingold, Eyal, Sheridan, Heather, Meadmore, Katie, Drieghe, Denis and Liversedge, Simon Paul orcid iconORCID: 0000-0002-8579-8546 (2016) Attention and eye-movement control in reading: the selective reading paradigm. Journal of Experimental Psychology: Human Perception and Performance, 42 (12). pp. 2003-2020. ISSN 0096-1523

It is advisable to refer to the publisher's version if you intend to cite from the work. http://dx.doi.org/10.1037/xhp0000291

For more information about UCLan's research in this area go to http://www.uclan.ac.uk/researchgroups/ and search for < name of research Group>.

For information about Research generally at UCLan please go to http://www.uclan.ac.uk/research/

All outputs in CLoK are protected by Intellectual Property Rights law, including Copyright law. Copyright, IPR and Moral Rights for the works on this site are retained by the individual authors and/or other copyright owners. Terms and conditions for use of this material are defined in the policies page.

\section{CLoK}

Central Lancashire online Knowledge www.clok.uclan.ac.uk

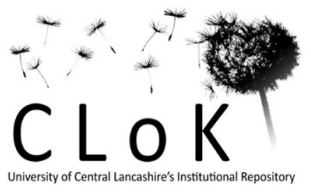


RUNNING HEAD: The selective reading paradigm

Attention and eye-movement control in reading: The selective reading paradigm

Eyal M. Reingold ${ }^{1}$, Heather Sheridan ${ }^{2}$, Katie L. Meadmore ${ }^{3}$, Denis Drieghe $^{3}, \&$ Simon P. Liversedge ${ }^{3}$

${ }^{1}$ University of Toronto at Mississauga, Mississauga, Ontario, Canada ${ }^{2}$ University at Albany State University New York, Albany, New York, U.S.A.

${ }^{3}$ University of Southampton, Southampton, U.K.

Key Words: eye movements, reading, lexical processing, word frequency, parafoveal preview, initial landing position, fixation location, fixation duration, covert attention.

Draft submitted to JEP: HPP; Do not cite without permission

Direct correspondence to:

Eyal Reingold

reingold@psych.utoronto.ca 
2 We introduced a novel paradigm for investigating covert attention and eye-movement control in

3 reading. In 2 experiments, participants read sentence words (shown in blue color) while ignoring

4 interleaved distractor strings (shown in orange color). Each single-line text display contained a

5 target word and a critical distractor. Critical distractors were located just prior to the target in the

6 text and were either words or symbol strings (e.g., @ @\# $\%$ ). Target word availability for

7 parafoveal processing (i.e., preview validity) was also manipulated. The results indicated much

8 shallower processing of distractors than targets and this pattern was more pronounced for symbol

9 than word distractors. The influences of word frequency and fixation location on first-pass

10 fixation durations on distractors were dramatically different than the well-documented pattern

11 obtained in normal reading. Robust preview benefits were demonstrated both when the critical

12 distractors were fixated and when the critical distractors were skipped. Finally, with the

13 exception of larger preview benefits that were obtained in the condition in which the target and

14 critical distractor were identical, the magnitude of the preview effect was largely unaffected by

15 the nature of the critical distractor. Implications of the present paradigm and findings to the study

16 of eye-movement control in reading are discussed. 
The use of eye movements to study reading has a rich history dating back over a century

2 (see Rayner, 1998, 2009, for reviews). Readers move their eyes primarily forward in the text to

3 encounter new words. The magnitude of the typical forward movement (saccade) for readers of

4 English is about 7-9 letter spaces. High-velocity saccadic eye movements, during which vision is

5 largely suppressed (Matin, 1974), occur at an average rate of 3-4 per second and are separated by

6 periods during which the eyes remain relatively still (fixations), and perceptual information is

7 extracted. Saccades are required in order to align the high-acuity foveal region of the retina (the

8 central $2^{\circ}$ of vision) with the part of the text that is being encoded by the reader. However,

9 during each fixation, while the fixated word $(\operatorname{word} N)$ is primarily encoded using foveal vision,

10 parafoveal vision is used to extract perceptual information from at least the next two words in the

11 text (word $N+1$ and $\operatorname{word} N+2)$. Specifically, for readers of English the encoding of useful

12 perceptual information is confined to the perceptual span, an asymmetric region of the text

13 around the fixation point, which is limited to about 3-4 letter spaces to the left and 14-15 letter

14 spaces to the right of fixation (McConkie \& Rayner, 1975). Importantly, when the area of useful

15 orthographic information during a fixation is restricted to $\operatorname{word} N$, word $N+1$ and $\operatorname{word} N+2$,

16 reading rate is approximately normal, while reading rate decreases by about $10 \%$ when only

17 Word $N$ and Word $N+1$ information is available and by over $30 \%$ when only Word $N$

18 information is available (Rayner, Slattery, \& Bélanger, 2010; Rayner, Well, Pollatsek, \& Bertera, 19 1982).

20 As demonstrated by Miellet, O'Donnell and Sereno (2009), the size of the perceptual

21 span is largely determined by attentional demands and not by the rapid visual acuity drop-off as a

22 function of the distance from the fovea. Specifically, these authors reported no increase in the

23 size of the perceptual span in an experimental condition in which they compensated for visual 
1 acuity drop-off by magnifying the size of letters as a function of their eccentricity (i.e., their

2 distance from fixation). Additional evidence for the important role of selective attention in

3 determining the size and shape of the perceptual span is derived from findings that despite their

4 proximity to the fovea, lines of text that are adjacent to the currently fixated line are not encoded

5 (Inhoff \& Briihl, 1991; Inhoff \& Topolski, 1994; Pollatsek \& Rayner, 1990) as well as from

6 findings that the size and shape of the perceptual span varies dramatically across languages (for a

7 recent review see Schotter, Angele, \& Rayner, 2012). Specifically, the asymmetry in the

8 perceptual span always favours the acquisition of information in the direction of reading as

9 compared to the opposite direction (e.g., greater encoding from the right side than left side of

10 fixation in English, but the reversed pattern in Hebrew; see Pollatsek, Bolozky, Well, \& Rayner,

11 1981). In addition, the high density of information in Chinese and Japanese scripts results in

12 substantially smaller perceptual spans (in terms of degrees of visual angle) in these languages

13 relative to English (e.g., Ikeda \& Saida, 1978; Inhoff \& Liu, 1998; see also Liversedge et al.,

14 2016), a finding that is consistent with the idea that attentional factors largely determine the size

15 of the perceptual span (for additional evidence see Kaakinen \& Hyönä, 2014).

16 Given the hypothesized importance of selective visual attention in determining the location

17 of the text to be foveated (i.e., fixation location) as well as in delimiting the duration of each

18 foveation (i.e., fixation duration), most current models of eye-movement control in reading

19 incorporate explicit assumptions concerning the influence of the allocation of attention on

20 various eye-movement parameters. One type of eye-movement control model in reading, which

21 is referred to as the Sequential Attention Shift (SAS) model, assumes serial lexical processing and

22 a tight coupling between attention and saccadic control in reading. An early version of this model

23 was proposed by Morrison (1984; see also Just \& Carpenter, 1980), and several modified 
1 versions aimed at extending it were later introduced (e.g., Henderson \& Ferreira, 1990;

2 Henderson, 1992; Kennison \& Clifton, 1995; Pollatsek \& Rayner, 1990; Rayner \& Pollatsek,

3 1989; Reichle, Pollatsek, Fisher, \& Rayner, 1998). The E-Z Reader model (Reichle et al., 1998;

4 for a review, see Reichle, 2011) constitutes the most prominent instantiation of the SAS model

5 and the first formal computational model of eye-movement control in reading. In contrast to the

6 concept of serial lexical processing that is central to SAS models, models assuming Guidance by

7 Attentional Gradient (GAG models) postulate that attentional resources are simultaneously

8 distributed across multiple words within the perceptual span and that lexical processing of these

9 words occurs in parallel. Similar to the perceptual span, the attentional gradient is assumed to be

10 asymmetrical, extending further in the direction of reading than in the opposite direction, with

11 more efficient processing of words near the center of the gradient than in the periphery.

12 Prominent computational models that incoporate such a proposal include SWIFT (Engbert,

13 Nuthmann, Richter, \& Kliegl, 2005) and Glenmore (Reilly \& Radach, 2003).

14 Thus, a key differentiation between models of eye-movement control in reading concerns

15 the manner in which covert attention mechanisms result in serial or parallel lexical processing of

16 words within the perceptual span. Currently, the controversy surrounding this issue is far from

17 being resolved (for recent reviews of this debate see Murray, Fischer, \& Tatler, 2013; Radach \&

18 Kennedy, 2013; Schotter et al., 2012). While the present investigation was informed in part by

19 the serial versus parallel lexical processing literature, the main goal of the present study was to

20 develop and explore a novel approach for the study of selective attention and eye-movement

21 control in reading. Specifically, the selective reading paradigm was designed for the purpose of

22 investigating the flexibility with which readers are able to attend to and process relevant target

23 words while ignoring irrelevant distractor words or symbol strings. Accordingly, in order to 
motivate the present paradigm, we begin by briefly considering research on eye-movement control in reading within the context of the broader literature on covert visual attention. We then

3 outline the rationale underlying the present paradigm and report results from two experiments

4 employing this paradigm.

$5 \quad$ Covert visual attention and eye-movement control in reading

There is a substantial body of research that has suggested that eye movements are typically

7 preceded by a covert attentional shift towards the saccadic target (e.g., Deubel \& Schneider,

8 1996; Henderson, 1993; Hoffman \& Subramaniam, 1995; Hoffman, 1998; Kowler, Anderson,

9 Dosher, \& Blaser, 1995; Rafal, Calabresi, Brennan, \& Sciolto, 1989; Rayner, McConkie, \&

10 Ehrlich, 1978; Remington, 1980; Schneider \& Deubel, 1995; Shepherd, Findlay, \& Hockey,

11 1986). Furthermore, covert orienting of attention has been shown to enhance perceptual

12 discriminability of stimuli within the attended region (e.g., Bashinski \& Bacharach, 1980; Briand

13 \& Klein, 1987; Downing, 1988; Eriksen \& Yeh, 1985; Jonides, 1980; for reviews see Carrasco

14 2011, 2014; Treue, 2004). In addition to perceptual enhancement within the attended region,

15 another consequence of both foveation (i.e., overt eye movements) and covert orienting of

16 attention is the selection of stimulus information for higher level cognitive processing (i.e., eye

17 movements and attentional shifts serve as a gating function; see Rensink, 2002; Simons, 2000).

18 Although the precise nature of the spatial distribution of covert attention is still unknown,

19 the existence of a location based selection mechanism operating early in visual processing is well

20 established. Specifically, in addition to behavioral studies, neurophysiological correlates of such

21 a mechanism were inferred from demonstrations that the retinotopic representations of attended

22 regions exhibit increased fMRI BOLD activation in humans (Brefczynski \& DeYoe, 1999;

23 Gandhi, Heeger, \& Boynton, 1999; Kastner, De Weerd, Desimone, \& Ungerleider, 1998; 
1 Martínez et al., 1999; Müller et al., 2003; Somers, Dale, Seiffert, \& Tootell, 1999; Tootell,

2 Hadjikhani, Mendola, Marrett, \& Dale, 1998) and increased neural firing in primate single-unit

3 recordings (Connor, Preddie, Gallant, \& Van Essen, 1997; Ito \& Gilbert, 1999; Luck, Chelazzi,

4 Hillyard, \& Desimone, 1997; Mcadams \& Maunsell, 2000; Moran \& Desimone, 1985; Reynolds,

5 Chelazzi, \& Desimone, 1999; Treue \& Maunsell, 1999).

Within the domain of reading, a very powerful demonstration of the role of covert attention emerged from investigations of the preview benefit for word $N+1$ which employed the invisible boundary paradigm (Rayner, 1975). This paradigm involves a manipulation of the availability of

9 target word information for parafoveal processing during fixations on pre-target words. The

10 critical contrast is between a valid preview condition which corresponds to normal reading (i.e.,

11 target words are available for parafoveal processing) versus an invalid preview condition in

12 which during fixations on pre-target words, a letter string (mask) occupies the position of the

13 target word in the sentence, and is replaced with the target word during a saccade that crosses an

14 invisible boundary located just prior to the location of the target word. The magnitude of the

15 preview benefit is typically measured by computing the increase in fixation times on target

16 words when parafoveal processing was prevented by presenting an unrelated letter string as a

17 preview compared to normal presentation (i.e., fixation times in the invalid minus the valid

18 preview condition). Using the invisible boundary paradigm, the word $N+1$ preview benefit has

19 been established as one of the most robust findings in the literature on eye-movement control in

20 reading (for reviews see Rayner, 1998, 2009; Schotter et al., 2012). Furthermore, lexical

21 parafoveal processing of word $N+1$ was demonstrated to play a crucial role in enabling rapid and

22 pervasive lexical control of fixation times in reading (Reichle \& Reingold, 2013; Reingold,

23 Reichle, Glaholt, \& Sheridan, 2012; Reingold, Sheridan, \& Reichle, 2015). 
Another critical influence of covert attention on eye-movement control in reading is

2 revealed by the fact that readers do not fixate (i.e., skip) between $10-30 \%$ of words in the text

3 (see Rayner, 1998, 2009), with increased probability of skipping for shorter words, more

4 frequent words, and words with higher contextual constraint (i.e., more predictable words).

5 Given intact comprehension, it is reasonable to assume that some skipped words are identified up

6 to a high degree parafoveally, thereby providing another illustration of facilitation of lexical

7 processing by covert attention. In addition, Reingold and Stampe (2004) demonstrated that

8 covert attention during reading produced an extremely rapid perceptual enhancement in the

9 direction of reading as compared to the opposite direction. Finally, taking into account the fact

10 that most saccades in reading are in the forward direction, the asymmetry of the perceptual span

11 might, at least in part, reflect covert orienting of attention towards the direction of the saccadic

12 target, that is, upcoming words that have not as yet been directly fixated. Thus, it is safe to

13 conclude that research on eye-movement control in reading has produced ample evidence for the

14 critical role of covert attention in determining both when the eyes move (i.e., fixation duration)

15 as well as where they move (i.e., fixation location). Consequently, as discussed below, it is not

16 surprising that models of eye-movement control in reading implicitly or explicitly incorporate

17 covert attention mechanisms as part of their architecture.

18 While SAS and GAG models are in general agreement about covert attention serving as a

19 visuospatial selection mechanism, there are important differences between these two

20 frameworks. Specifically, SAS models are based on the spotlight metaphor of covert attention

21 (see Inhoff, Pollatsek, Posner, \& Rayner, 1989; Posner, Snyder, \& Davidson, 1980). Text

22 information inside the spotlight is assumed to be perceptually enhanced and prioritized for

23 lexical processing as compared to information outside the spotlight, and the progression of this 
1 spotlight is strictly serial. Lexical units are typically assumed to correspond to a single word,

2 and units are "illuminated" sequentially one at a time. Importantly, the spotlight has a well-

3 defined boundary such that enhanced processing is distributed in an all-or-none manner (i.e., the

4 processing of text information outside the attentional beam is not facilitated regardless of its

5 proximity to the attended region).

In contrast to the spotlight metaphor, GAG models, are based on the Attentional Gradient metaphor (Downing \& Pinker, 1985; LaBerge \& Brown, 1989; Shulman, Sullivan, Gish, \&

8 Skaoda, 1986; Shulman, Wilson, \& Sheehy, 1985). GAG models describe the spatial distribution

9 of covert attention in terms of an asymmetric gradient (similar in extent to the perceptual span).

10 Rather than an all-or-none attentional distribution, GAG models suggest that enhanced

11 processing of text information is greatest at the center of the fixated region and falls off gradually

12 with distance. The attentional gradient concept was further extended in recent formulations of

13 SWIFT (e.g., Schad \& Engbert, 2012) that incorporated dynamic modulation of the size of the

14 covertly attended region as an inverse function of the processing difficulty of the fixated word.

15 This concept of the dynamic modulation of the attentional gradient was inspired by the zoom-

16 lens metaphor of covert attention (e.g., Eriksen \& St James, 1986).

In comparison to the spotlight concept, the attention gradient is larger and does not require

18 precise aiming due to its broader extent of coverage. The larger attended region defined by the

19 gradient likely has a processing cost as well. This suggestion is supported by studies which

20 demonstrated that when attention was distributed over a larger region of the visual field, there

21 was reduced spatial resolution and reduced processing efficiency for any smaller area within the

22 attended region (Castiello \& Umiltá, 1990; 1992; Eriksen \& Murphy, 1987; Eriksen \& Schultz,

23 1977; Eriksen \& St James, 1986; Eriksen \& Yeh, 1985; Eriksen, 1990; Shulman \& Wilson, 
1 1987). In addition, as compared to the spotlight all-or-none distribution of attention, the

2 attentional gradient with its larger size and ill-defined boundary might be less effective in

3 excluding or filtering out irrelevant information that is located near the attended location.

4 The present Paradigm

The Selective Reading Paradigm introduced in the present paper involves inserting

6 irrelevant words or nonwords into the text, while clearly differentiating between the constituents

7 of the sentence and the distractor words by using a salient perceptual cue (color in the present

8 experiments) that can be efficiently processed parafoveally. There is substantial evidence from

9 studies of visual search that parafoveal and peripheral processing of perceptual features such as

10 color and shape is commonly used to guide saccades (for reviews see Reingold \& Glaholt, 2014;

11 Zelinsky, 2008). Specifically, analyses of the distribution of saccadic endpoints have

12 convincingly demonstrated a bias towards fixating distractors that are similar to a target (i.e.,

13 share features with the target) as compared to dissimilar distractors (e.g., Findlay, Brown, \&

14 Gilchrist, 2001; Findlay \& Gilchrist, 1998; Hooge \& Erkelens, 1999; Pomplun, Reingold, \&

15 Shen, 2001, 2003; Scialfa \& Joffe, 1998; Williams \& Reingold, 2001) and such saccadic

16 selectivity has been shown to be extremely flexible in rapidly adapting to changes in the

17 characteristics of the search array (e.g., Shen, Reingold, \& Pomplun, 2000; see also Reingold \&

18 Glaholt, 2014 for a demonstration of saccadic selectivity and preview benefit in visual search).

19 Whilst the inclusion of distractors means that the presentation of the text in the present

20 paradigm differs from the standard procedure used in laboratory experiments, it is important to

21 note that text presented in real world conditions (e.g., mobile devices, websites) is often

22 intermingled with salient irrelevant distractors in the form of symbols, images, icons or

23 messages. More importantly, the inclusion of distractors in the text has several advantages for the 
1 investigation of covert attention in reading. Specifically, depending on the spatial arrangement of

2 distractors versus relevant text, it is possible to manipulate the distance and spatial relationship

3 between two successive words in the text (e.g., by inserting a distractor between them). Given

4 that efficient selective reading requires that distractors be excluded or filtered, the present

5 paradigm allows us to explore how covert attention might permit the suppression of irrelevant

6 information during reading. Such a role for covert attention in reading is consistent with the

7 finding that despite its proximity to fixation, text on adjacent lines is not linguistically processed

8 (Inhoff \& Briihl, 1991; Inhoff \& Topolski, 1994; Pollatsek, Raney, Lagasse, \& Rayner, 1993).

9 Furthermore, this finding indicates that regardless of whether attention is allocated in a discrete

10 precisely bounded way, or in a graded manner in the horizontal dimension, it is clearly very

11 precisely bounded in relation to its vertical spread. More importantly for the present study,

12 investigations of visual attention in both humans and primates have demonstrated a role for

13 covert attention not only in facilitating the processing of information within the attended region,

14 but also in actively suppressing distractor information (e.g., Cepeda, Cave, Bichot, \& Kim, 1998;

15 Gaspar \& McDonald, 2014; Moran \& Desimone, 1985). Consequently, the inclusion of

16 distractors in the selective reading paradigm might be useful for studying the inhibitory

17 component of covert attention in reading.

18 The selective reading paradigm has an additional useful characteristic. Through

19 manipulation of the lexical status and characteristics of the distractor stimuli, it is possible to

20 investigate the depth with which those distractors are processed either when directly foveated or

21 when skipped. For example, given that word frequency effects constitute a primary empirical

22 marker for lexical processing (e.g., Inhoff \& Rayner, 1986; Rayner \& Duffy, 1986; Rayner,

23 1977; Reingold et al., 2012), using word distractors which vary in frequency allows us to 
1 determine whether or not distractors are obligatorily lexically processed. To be clear, in using

2 the term obligatory, we mean processing that is automatic, reflexive and mandatory, as per Fodor

3 (1983). Obligatory lexical processing might be predicted by interpretations of the famous Stroop

4 effect (Stroop, 1935; see MacLeod, 1991 for review) as demonstrating involuntary or automatic

5 word identification by skilled readers even when it may be detrimental to task performance

6 (though for an opposing view see Besner, Stolz \& Boutilier, 1997). Furthermore, the selective

7 reading paradigm allows for examination of the extent to which various eye-movement

8 parameters are impacted by the relevance of the fixated text. Finally, by employing our paradigm

9 in conjunction with the boundary technique (Rayner, 1975) that was described earlier, it is

10 possible to examine the impact of including distractors on the efficiency of parafoveal processing

11 as measured by the magnitude of the preview benefit.

Experiments 1 and 2

In the next section we will report data from two experiments. We present these results

14 together due to their degree of commonality in terms of method and experimental manipulation.

15 In both experiments we presented participants with sentences including embedded distractor

16 strings on a single line for them to read. Relevant sentence words were presented in blue color

17 while distractor strings were shown in orange color. Specifically, a distractor (four characters in

18 length) was presented between each successive pair of words in the sentence. Also, each

19 sentence contained a target word and a critical distractor string immediately prior to the target

20 (see Figure 1). Target word availability for parafoveal processing (i.e., valid vs. invalid preview

21 condition) was manipulated using the boundary paradigm (Rayner, 1975) with the invisible

22 boundary positioned in the middle of the space between the critical distractor and the target

23 word. As shown in Figure 1, in both experiments the target word was a four-letter word (e.g., 
1 pipe). In Experiment 1, the critical distractor was either a high frequency word (e.g., next), a

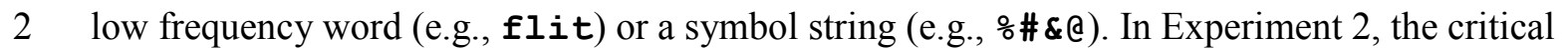

3 distractor was either the same word as the target (repeated condition, e.g., pipe), an unrelated

4 frequency-matched word (control condition, e.g., chip), or a symbol string (e.g., #\#\&@). In

5 addition to preview validity and distractor type, after the experiment, trials were also classified

6 based on whether or not the critical distractor was skipped (henceforth, distractor-skipped trials)

7 or fixated (henceforth, distractor-fixated trials) in first pass reading. Finally, if target preview

8 benefits were obtained in either distractor-skipped or distractor-fixated trials, it would be

9 important to establish whether or not such effects are modulated by distractor type (e.g., symbol

10 vs. word in both Experiments 1 and 2; high vs. low frequency word in Experiment 1; repeated

11 word vs. unrelated matched control word in Experiment 2).

\section{Method}

13 Participants. A total of 60 students or volunteers (30 in each of the two experiments) were

14 tested at the University of Southampton. None of the participants in Experiment 1 were included

15 in Experiment 2. All participants had normal or corrected-to-normal vision and normal color

16 vision (assessed using Ishihara plates; Ishihara, 1964). The participants were all native English

17 speakers. They were naïve with respect to the purpose of the experiment and received either

18 course credit or $£ 6$ per hour for their participation.

Materials and design. A total of 300 4-letter words were used as target words $(\mathrm{M}=43.9$

20 words per million; Van Heuven, Mandera, Keuleers, \& Brysbaert, 2014). Low-constraint

21 sentence frames were composed for each of the 300 target words (Predictability $<.01 \%$ as

22 estimated by collecting cloze-task sentence completion norms from a separate group of 10

23 participants). All sentences were 7 words in length and the target word appeared in position 3, 4 
or 5 in the sentence. For each of the 300 sentences, a distractor (4 letter spaces in length) that

2 was either a word or a string of symbols was presented between each pair of words in the

3 sentence for a total of 6 distractors per sentence (see Figure 1). Importantly, each sentence

4 contained one critical distractor that was presented immediately prior to the target word, and

5 which was manipulated across experimental conditions. The other 5 non-critical distractors and

6 all the words in the sentence including the target word did not vary across experimental

7 conditions. Across all of the sentences in both experiments, approximately half of the non-

8 critical distractors were words and the other half were symbol strings.

9 In Experiment 1, each participant was shown 100 sentences with a high frequency critical

10 distractor $(M=831.8$ words per million; Van Heuven et al., 2014), 100 sentences with a low

11 frequency critical distractor $(\mathrm{M}=0.2$ words per million, Van Heuven, et al., 2014), and 100

12 sentences with a 4-symbol string as a critical distractor (symbol distractors were created by

13 randomly choosing 1 of 24 unique combinations of $@$, \#, $\frac{\circ}{\circ}$ and \&). In Experiment 2, each

14 participant was shown 100 sentences in the symbol condition (which was identical to Experiment

15 1), 100 sentences in the repeated condition that contained a critical distractor that was identical to

16 the target word, and 100 sentences in the control condition that contained a critical distractor that

17 was matched on frequency to the target ( $M=44.2$ words per million; Van Heuven et al., 2014).

18 In both Experiments 1 and 2, in addition to the distractor type manipulation, on half of the

19 trials (valid preview trials), the sentences appeared normally, while in the other half of the trials

20 (invalid preview trials), a pronounceable 4-letter non-word (see Figure 1) was initially displayed

21 in the target location and was replaced with the target word during the saccade that crossed an

22 invisible boundary located in the middle of the space between the critical distractor and the

23 target. Thus, 6 experimental conditions resulted in each experiment from crossing Distractor type 
1 (Experiment 1: high frequency condition, low frequency condition, symbol condition;

2 Experiment 2: repeated condition, control condition, symbol condition) and Preview validity

3 (valid vs. invalid). Each participant read any given target word and sentence frame only once and

4 the assignment of critical distractor words to sentence frames and preview conditions was

5 counterbalanced across participants. Participants read 6 practice sentences followed by 300

6 experimental sentences that were presented in a random order.

Apparatus and Procedure. The apparatus and procedure were identical in Experiments 1

8 and 2. Eye movements were measured with an SR Research EyeLink 1000 Plus system with a

9 sampling rate of $1000 \mathrm{~Hz}$. Viewing was binocular, but only the right eye was monitored. A chin

10 rest and forehead rest were used to minimize head movements. Following calibration, average

11 gaze-position error was less than $0.5^{\circ}$. The sentences were presented on a 24 inch Asus

12 VG248QE monitor with a refresh rate of $144 \mathrm{~Hz}$ and a screen resolution of $1920 \mathrm{x} 1080$ pixels.

13 All letters were lowercase (except where capitals were appropriate) and were shown in bold

14 mono-spaced Courier New font. The letters were presented either in blue or orange on a white

15 background (the words in the sentence were in blue and distractors were in orange; RGB Values:

$160,0,255$ [blue] and 255, 102, 0 [orange]). Participants were seated $95 \mathrm{~cm}$ from the monitor and 4

17 characters equalled approximately 1 degree of the visual angle. In both Experiments 1 and 2,

18 participants were told to read the blue sentence for comprehension and to ignore the orange text.

19 At the beginning of a trial, participants were required to fixate a cross on the left hand side of the

20 screen and to press a button. This triggered the text to appear. After reading the sentence,

21 participants pressed a button to end the trial and proceed to the next trial. To ensure that

22 participants were reading for comprehension, about $17 \%$ of the experimental sentences were

23 followed by multiple-choice comprehension questions. 
The average comprehension accuracy rates were very high (Experiment $1=98 \%$;

3 Experiment $2=97 \%$ ). We examined the influence of the Preview validity by Distractor type

4 manipulation on several eye-movement parameters pertaining to the processing of the target

5 word and the critical distractor in both experiments. Trials were excluded from the analyses

6 described below due to track losses ( $0.01 \%$ of all trials). In the invalid preview conditions, trials

7 in which the invisible boundary was crossed during a fixation were also excluded $(11.3 \%$ of

8 invalid preview trials). In addition, trials in which there was no first-pass fixation on either the

9 target or the critical distractor (i.e. they were both skipped) were also excluded from the analyses

$10 \quad(0.07 \%$ of all trials). We begin by reporting the results from an analysis of the proportion of

11 skipping. Next, we will examine the impact of our experimental manipulations on first-pass

12 fixation duration measures. Finally, we will investigate differences in fixation location across

13 experimental conditions as well as the impact of fixation location on other aspects of saccadic

14 performance.

15 Proportion of Skipping

16 A crucial component of the selective reading paradigm is the availability of a salient

17 perceptual cue (color in the present experiments) that clearly distinguishes the relevant text from

18 the irrelevant distractor text, and which would be expected to produce higher skipping rates for

19 distractors than for sentence words. We investigated variations across experiments and

20 conditions in the proportion of skipping of either the target or the critical distractor. Analyses of

21 variance $(A N O V A \mathrm{~s})$ were conducted on the proportion of skipping data via both subjects $\left(F_{1}\right)$ and

22 items $\left(F_{2}\right)$. Figure 2 shows the proportion of distractor skipping (top panel) and proportion of

23 target skipping (bottom panel) by experimental condition in Experiments 1 and 2. As can be seen 
1 in the figure, while the proportions of target skipping were within the normal range of reading

2 performance (Brysbaert, Drieghe, \& Vitu, 2005), skipping rates for the critical distractor across

3 all conditions and experiments were much higher, and this occurred despite the fact that the

4 target and distractor were matched on length (all $F \mathrm{~s}>297.8$, all $p \mathrm{~s}<.001$ ). This result

5 demonstrates clearly that readers were able to use color cues associated with parafoveal words to

6 modulate their saccadic targeting during reading.

7 Proportion of Skipping: Critical distractor

8 To examine the pattern in more detail, for each experiment, $2 \times 3$ ANOVAs were carried

9 out, with Preview validity and Distractor type as independent variables. The pattern of skipping

10 rates for the critical distractor was consistent across experiments. Specifically, the main effect of

11 Distractor type was significant (all $F_{\mathrm{s}}>55.4$, all $p \mathrm{~s}<.001$ ), but neither the main effect of

12 Preview validity (all $F \mathrm{~s}<1$ ) nor the interaction between Distractor type and Preview validity

13 approached significance (all $F \mathrm{~s}<1.8$, all $p \mathrm{~s}>.17$ ). In addition, planned comparisons indicated

14 that in both experiments the proportion of skipping was substantially higher when the critical

15 distractor was a symbol string than when it was a word (all $t \mathrm{~s}>6.2$, all $p \mathrm{~s}<.001$ ). Clearly word

16 distractors captured attention, and more critically a fixation, to a greater degree than symbol

17 distractors. Consequently, although saccadic selectivity due to parafoveal processing of

18 distractors was primarily driven by the color cue, the potential relevance of distractors to the

19 reading task also exerted a sizable influence on distractor skipping rates with the linguistically

20 meaningless symbol distractors being skipped more often than the linguistically meaningful

21 word distractors. In addition, in Experiment 1, there was a small but significant increase in

22 skipping rates when the distractor was a high frequency word than a low frequency word $\left[t_{1}(29)\right.$

$\left.23=2.19, p<0.05 ; t_{2}(299)=3.14, p<0.01\right]$. In contrast, in Experiment 2, skipping rates did not 
1 differ between the two word distractor conditions (repeated vs. control) that were matched on

2 word frequency. Finally, we also evaluated the influence of practice on distractor skipping rates

3 by comparing skipping performance during the first half versus the second half of each

4 experiment. The only significant effect of practice was a small increase in the probability of

5 skipping of word distractors (first half: 0.535 , second half: $0.567 ; t(59)>2.7, p<.01$ ). There

6 were no other significant effects or interactions with practice (all $F \mathrm{~s}<1$ ). Taken together, the

7 present findings demonstrate that parafoveal processing of distractors was not restricted to their

8 color; the word/symbol and word frequency effects demonstrate some form of parafoveal

9 orthographic (and likely phonological) processing and some parafoveal lexical processing of

10 distractors.

11 Proportion of Skipping: Target word

As shown in Figure 2 (bottom panel), in both Experiment 1 and 2, when critical distractors

13 were fixated, the next word (i.e., the target word), was more likely to be skipped in the case of

14 symbol distractors than word distractors (all $t \mathrm{~s}>2.33$, all $p \mathrm{~s}<.05$ ). Further examination of the

15 proportion of target skipping in Experiment 1 indicated that the target was numerically more

16 likely to be skipped when the distractor was a high frequency word than a low frequency word,

17 and this effect was marginally significant by subjects $\left[t_{1}(29)=1.81, p=0.08\right]$ and significant by

18 items $\left[t_{2}(299)=2.51, p<0.05\right]$. Thus, in Experiment 1 , fixating distractors that were more likely

19 to be skipped (symbol $>$ high frequency $>$ low frequency) resulted in higher rates of target

20 skipping. This pattern might suggest that the influence of Distractor type on target skipping rates

21 was due to the modulation of parafoveal processing of the target during fixations on the critical

22 distractor. That is, fixating distractors that were easier to process and discard might have

23 facilitated parafoveal processing of the targets leading to an increase in target skipping rates. 
1 Such an interpretation would be consistent with the foveal load hypothesis (Henderson \&

2 Ferreira, 1990), which stipulates that when foveal processing load is high, parafoveal processing

3 of upcoming words is reduced. However, if this interpretation was correct then such a

4 modulation should have been largely restricted to the valid preview condition in which target

5 information was available for parafovoeal processing. This prediction was not supported by the

6 analysis of target skipping rates in Experiment 1, which indicated that there was no main effect

7 of Preview validity and no interaction between Preview validity and Distractor type (all $F_{\mathrm{s}}<1$ ).

8 In marked contrast to Experiment 1, the analysis of target skipping data in Experiment 2

9 produced a significant interaction between Preview validity and Distractor type $\left[F_{1}(2,58)=4.0, p\right.$

$\left.10<0.05 ; F_{2}(2,598)=4.7, p<0.01\right]$. Specifically, in invalid preview trials the symbol condition

11 produced higher skipping rates (all $t \mathrm{~s}>3.84$, all $p \mathrm{~s}<.001$ ) than either of the 2 word distractor

12 conditions which did not differ (i.e., repeated vs. control; all $t$ s $<1$ ). While, in valid preview

13 trials the probability of target skipping in the repeated condition and the symbol condition did

14 not significantly differ (all $t \mathrm{~s}<1$ ), and both of these conditions exhibited higher skipping rates

15 than in the control condition (all $t \mathrm{~s}>2.14$, all $p \mathrm{~s}<.05$ ). Thus, it appears that when the target

16 was available for parafoveal processing (i.e., valid preview), fixating a critical distractor that was

17 identical to the target increased the likelihood of target skipping as compared to fixating a

18 distractor that was unrelated to the target. In contrast, when parafoveal processing was rendered

19 ineffective (i.e., invalid preview) the repeated and control conditions did not differ. In other

20 words, there is clear evidence that the parafoveal processing of the target word was facilitated or

21 "primed" during a fixation on an identical critical distractor. 
1 Fixation durations

2 We examined the influence of the Distractor type by Preview validity manipulation on

3 first-pass fixation durations on both the target word and the critical distractor. Specifically, we

4 analyzed variation in first-fixation duration (i.e., the duration of the first forward fixation on the

5 target or the distractor, regardless of the number of subsequent fixations), and gaze duration (i.e.,

6 the sum of all the consecutive first-pass fixations on the target or the distractor, prior to a saccade

7 to another part of the text). In addition, in both Experiments 1 and 2, these first-pass duration

8 measures were computed separately for fixations on the critical distractor, fixations on the target

9 word in trials in which the critical distractor was fixated (distractor-fixated trials), and fixations

10 on the target word in trials in which the critical distractor was skipped (distractor-skipped trials).

11 Figure 3 illustrates the findings from the analysis of mean first-fixation duration and gaze

12 duration by experimental condition in Experiments 1 and 2. As was the case for skipping rates,

13 there was a very robust effect of sentence relevance (i.e., target vs. distractor) on first-pass

14 fixation durations. Specifically, across all experimental conditions in both experiments, first-

15 fixation duration and gaze duration on the critical distractor were substantially shorter than the

16 corresponding values on the target word (all $F \mathrm{~s}>263.9$, all $p \mathrm{~s}<.001$ ). These results, along with

17 the skipping data, suggest that despite minimal practice participants were adept at modifying

18 their reading behavior to suppress irrelevant distractor information. For the most part, distractors

19 were discarded based on parafoveal processing and were either skipped or fixated only briefly.

20 These findings clearly demonstrate flexible and precise allocation of covert attention in the

21 selective reading paradigm. 
1 First-pass fixation durations: Critical distractor

In order to further analyze fixation times on the critical distractor, for each dependent

3 measure, 2 x 3 ANOVAs with Preview validity and Distractor type as independent variables

4 were carried out via subjects and items in both Experiment 1 and 2. Across all analyses, the main

5 effect of Distractor type was significant (all $F \mathrm{~s}>20.8$, all $p \mathrm{~s}<.001$ ) but there was no significant

6 main effect of Preview validity (all $F \mathrm{~s}<1.5$, all $p \mathrm{~s}>.22$ ) or interaction between Distractor type

7 and Preview validity (all $F \mathrm{~s}<1.7$, all $p \mathrm{~s}>.22$ ). This pattern of results mirrors the effects that we

8 observed for the distractor skipping data. As was the case for skipping rates, the analysis of first-

9 pass fixation duration measures indicated that readers spent longer processing word distractors

10 than symbol distractors (all $F \mathrm{~s}>11.0$, all $p \mathrm{~s}<.001$ ), a finding consistent with the suggestion of

11 truncated processing of non-linguistic (i.e., symbol) as compared to linguistic (i.e., word)

12 distractors. There was also a numerical trend indicating a slight processing advantage for high

13 frequency than low frequency distractors in Experiment 1 (i.e., numerically shorter fixation times

14 for high frequency than low frequency distractors; first-fixation: $F_{1}(1,29)=3.7, p=0.07$;

$15 \quad F_{2}(1,299)=4.6, p<0.05$; gaze duration: $\left.F_{1}(1,29)=1.9, p=0.18 ; F_{2}(1,299)=2.6, p=0.11\right)$. In

16 addition, in Experiment 2, first-pass fixation duration measures did not differ across the two

17 word distractor conditions (repeated vs. control) which were matched on word frequency (all $F \mathrm{~s}$

18 1). Finally, there was no significant influence of practice on fixation durations on distractors

19 (all $F \mathrm{~s}<1)$. Overall, the pattern of first-pass fixation durations on distractors closely resembles

20 the findings observed for the distractor skipping data in Experiments 1 and 2.

21 First-pass fixation durations: Target word

To examine first-pass fixation durations on the target word, for each experiment and dependent measure, $2 \times 3 \times 2$ ANOVAs were carried out via subjects and items with Preview 
1 validity, Distractor type, and Trial type (i.e., fixated-distractor trials vs. skipped-distractor trials)

2 as independent variables. All of these analyses produced significant main effects of Preview

3 validity reflecting significant preview benefits (i.e., shorter first-pass fixation times in valid

4 preview than invalid preview) for both distractor-fixated trials (all $F \mathrm{~s}>52.6$, all $p \mathrm{~s}<.001$ ) and

5 distractor-skipped trials (all $F_{\mathrm{s}}>10.7$, all $p \mathrm{~s}<.01$ ). However, the size of the preview benefit was

6 significantly larger for distractor-fixated trials than distractor-skipped trials, and this was

7 reflected in significant interactions across all analyses between Preview validity and Trial type

8 (all $F \mathrm{~s}>24.7$, all $p \mathrm{~s}<.001$ ). This pattern presumably occurs because the fixation prior to the

9 first fixation on the target word was at least one word further away from the target in the case of

10 distractor-skipped trials than distractor-fixated trials. In light of this difference, it is not

11 surprising that smaller preview effects were obtained in the former than the latter condition, and

12 this finding likely reflects the fact that parafoveal processing of the target was more efficient

13 when readers were in closer proximity to the target. More importantly, despite the increase in

14 distance and associated visual acuity limitations, we obtained robust preview benefits in

15 distractor-skipped trials. We will return to this point in the discussion.

16 In addition, across all analyses in Experiment 1, there was a main effect of Distractor

17 type (all $F \mathrm{~s}>5.6$, all $p \mathrm{~s}<.01)$ reflecting shorter first-pass fixation times on the target word for a

18 symbol distractor than for either of the 2 word distractor conditions (all $F \mathrm{~s}>3.9$, all $p \mathrm{~s}<.05$ )

19 which did not significantly differ (despite a numerical difference showing shorter first-pass

20 fixation times on the target word for high frequency than low frequency distractors; all $F_{\mathrm{S}}<1.4$,

21 all $p \mathrm{~s}>$.24). A similar effect to this was also reported by Risse and Kliegl, (2014). Again,

22 though, as with the target skipping results, shorter target word fixation times occurred in the case 
1 of a symbol distractor regardless of Preview validity indicating that Distractor type did not

2 modulate the size of the preview benefit (all $F \mathrm{~s}<2.0$, all $p \mathrm{~s}>.14$ ).

In marked contrast to Experiment 1, the analyses of first-pass fixation times on the target

4 word in Experiment 2 demonstrated significant interactions between Distractor type and Preview

5 validity (all $F \mathrm{~s}>4.1$, all $p \mathrm{~s}<.05$ ). To further explore this modulation of the size of the preview

6 benefit by Distractor type in Experiment 2, we contrasted each pair of Distractor type conditions

7 (repeated vs. control, repeated vs. symbol, control vs. symbol) using $2 \times 2 \times 2$ ANOVAs that

8 were carried out via subjects and items with Preview validity, Distractor type, and Trial type as

9 independent variables. These analyses demonstrated larger preview benefits in the repeated

10 condition than in either the control condition or the symbol condition (all $F_{\mathrm{s}}>7.5$, all $p \mathrm{~s}<.01$ ),

11 and the control and symbol conditions did not significantly differ (all $F \mathrm{~s}<1$ ). Once again, there

12 is considerable consistency between the skipping data and the fixation duration data across the

13 two experiments. As with the skipping data, there appears to have been sensitivity to the identity

14 of the distractor when it was the same as the target relative to when it was not. Presumably, a

15 distractor that was identical to the target facilitated or "primed" parafoveal processing of the

16 target resulting in a greater likelihood of the target being skipped and shorter first-pass fixation

17 durations when it was fixated. Thus, Experiments 1 and 2 demonstrated two qualitatively

18 different effects of the type of fixated distractors on target processing: 1) easier to process

19 distractors produced higher rates of skipped targets and shorter first-pass fixation durations on

20 targets regardless of preview validity, and 2) distractors which were identical to the targets

21 increased target skipping rates and produced shorter first-pass fixation durations, but only when

22 targets were available for parafoveal processing (i.e., valid preview). 
1 Fixation location

Figure 4 shows differences in the location of the first fixation (i.e., initial landing position)

3 on the target word (Panel a) and on the critical distractor (Panel b). There were no significant

4 differences in the mean initial landing position (all $F_{\mathrm{s}}<1$ ) between: 1) valid versus invalid

5 preview, 2) Experiment 1 versus Experiment 2, and 3) different word distractor conditions (high

6 frequency, low frequency, repeated and control). Consequently, the results are shown collapsed

7 over these conditions. Note that the lack of effects of different distractors on landing positions is

8 in contrast with the effects observed for the fixation duration measures. This supports the

9 suggestion that decisions about where and when to move the eyes are made independently (see

10 Findlay \& Walker, 1999).

11 Fixation location: Landing positions

12 As can be seen in Figure 4 (Panels a and b), there was a dramatic difference in the

13 distribution of first-fixation landing locations between the target words and the critical

14 distractors. In order to quantify this difference, we classified initial fixations as central fixations

15 if they landed on the 2 center letter bins (i.e., letters 2 and 3 of a four letter word), while all other

16 fixations were classified as outer fixations. Whereas the distribution of initial fixation locations

17 on the target word replicated prior findings showing more central than outer fixations (Dunn-

18 Rankin, 1978; McConkie, Kerr, Reddix, \& Zola, 1988; Rayner, 1979; Vitu, O’Regan, \& Mittau,

19 1990), the reverse pattern occurred for initial fixation locations on the critical distractor, and this

20 interaction was highly significant $(F(1,58)=108.9, p<0.001)$. Furthermore, for initial fixations

21 on the critical distractor there was a higher proportion of central fixations for word distractors

22 than for symbol distractors $(t(59)=3.36, p<0.001)$, but there was no such effect of Distractor

23 type on the proportion of central fixations on the target word $(t<1)$. These differences might 
1 indicate that mislocated fixations (either due to saccadic overshoot or undershoot) represent a

2 smaller proportion of the total number of fixations on target words relative to the corresponding

3 proportion of mislocated fixations on critical distractors. In particular, a large proportion of

4 fixations on the non-linguistic symbol distractors might constitute mislocated fixations.

$5 \quad$ Fixation location: Modulation of first and single fixation durations

Next, we conducted $2 \times 2 \times 2$ ANOVAs with Location (central vs. outer) by Distractor type

7 (symbol vs. word) by Text type (target word vs. critical distractor) as independent variables, and

8 first-fixation duration, single fixation duration (i.e., the first-fixation duration value for the subset

9 of trials in which there was only one first-pass fixation), and the proportion of refixations (i.e.,

10 the proportion of trials in which multiple first-pass fixations occurred), as dependent variables.

11 As can be seen in Figure 4, for the target word we replicated prior findings (e.g., Nuthmann,

12 Engbert, \& Kliegl, 2005; Vitu, McConkie, Kerr, \& O’Regan, 2001; for a review see Vitu,

13 Lancelin, \& Marrier d'Unienville, 2007) demonstrating that first-fixation durations and single

14 fixation durations were longer for central than outer fixations (first-fixation: word distractor,

$15 t(59)=5.89, p<0.001$, symbol distractor, $t(59)=4.69, p<0.001$; single fixation: word

16 distractor, $t(59)=3.96, p<0.001$, symbol distractor, $t(59)=2.64, p<0.05)$. In contrast, for the

17 critical distractor (see Figure 4, Panels d and f), outer fixations were longer than central fixations

18 (first-fixation: word distractor, $t(59)=3.99, p<0.001$, symbol distractor, $t(59)=7.09, p<0.001$;

19 single fixation: word distractor, $t(59)=3.87, p<0.001$, symbol distractor, $t(59)=6.68, p<$

20 0.001). This difference in the pattern of fixation times was reflected in significant interactions

21 between Text type and Location (first-fixation: $F(1,58)=116.4, p<0.001$; single fixation:

$22 \quad F(1,58)=83.4, p<0.001)$. 
1 Fixation location: Refixations

Another striking difference between the target word and the critical distractor concerns the

3 impact of fixation location on the proportion of refixations (see Figure 4 Panels g-h). Trials with

4 refixations on the critical distractor were very uncommon and the proportion of such trials did

5 not vary between central and outer initial fixations (both $t s<1$ ). In marked contrast, the pattern

6 of refixations on the target word replicated the typical findings in the literature (for a review see

7 Vitu et al., 2007) demonstrating a higher proportion of refixations for outer than central initial

8 fixations (both $t \mathrm{~s}>8.83$, both $p \mathrm{~s}<.001$ ). This difference in the pattern of refixation data was

9 reflected in significant interactions between Text type and Location $(F(1,58)=101.4, p<0.001)$.

10 These differences in the pattern of results for refixations on the target words compared with the

11 critical distractors are dramatic. Readers were approximately four times more likely to make a

12 refixation on a target than on a distractor. Furthermore, for the target words refixations were

13 over twice as likely when an outer rather than an inner letter was initially fixated, whilst for

14 distractor strings, there was little difference. Overall, the initial landing position effects are very

15 consistent with the suggestion that readers modified their reading behavior in order to maximally

16 selectively attend to the content words and actively suppress the acquisition of information from

17 irrelevant distractors.

\section{Discussion}

19 The implementation of the selective reading paradigm in Experiments 1 and 2 yielded a

20 striking pattern of differences between the processing of target words and critical distractors.

21 Specifically, in comparison to targets, distractors were much more likely to be skipped or briefly

22 fixated and much less likely to be refixated, and these findings clearly indicate much shallower

23 processing of distractors than targets. Furthermore, the depth to which the distractors were 
1 processed also depended upon their linguistic characteristics. Readers devoted more processing

2 resources to words than symbol distractors, and numerically, more to distractors which were low

3 frequency words than high frequency words. In addition to these quantitative differences, the

4 processing of distractors appears qualitatively different than normal reading. In particular, first-

5 pass fixation times on critical distractors demonstrated greatly attenuated effects of word

6 frequency in comparison to normal reading. Given that word frequency effects constitute a

7 primary empirical marker for lexical processing (Inhoff \& Rayner, 1986; Rayner \& Duffy, 1986;

8 Rayner, 1977; Reingold et al., 2012), the present findings suggest that lexical processing of word

9 distractors was greatly reduced. The attenuation of lexical processing of irrelevant distractors in

10 the current paradigm is similar to the findings that during mind-wandering episodes (sometimes

11 referred to as mindless reading), word-frequency effects are absent or much reduced in size (e.g.,

12 Reichle, Reineberg, \& Schooler, 2010; Schad, Nuthmann, \& Engbert, 2012). Thus, it seems that

13 reading in the absence of attentional engagement or with active attentional suppression is

14 qualitatively different than normal reading.

15 Similar to the influence of word frequency, the landing position of the first-fixation on a

16 word (i.e., central vs. outer fixations) is known to exert very robust and consistent effects on eye-

17 movement parameters in normal reading. Accordingly, the remarkable differences between

18 targets and distractors in terms of the distributions of fixation location and in the impact of this

19 variable on eye movements (see Figure 4) constitute another dramatic illustration that the

20 processing of irrelevant text within the selective reading paradigm is qualitatively different than

21 normal reading. It is noteworthy that location effects on eye-movement control in reading have

22 been demonstrated to be extremely rapid and are typically assumed to be mediated by a non-

23 lexical control mechanism (e.g., Nuthmann et al., 2005; Nuthmann, Engbert, \& Kliegl, 2007; 
1 Vitu et al., 2001, 2007). Importantly, the present findings suggest that, just like word frequency

2 effects, location effects in reading might not be immune to the influence of top-down attentional

3 factors. Furthermore, it is interesting to consider the theoretical implications of the finding that

4 location effects (i.e., initial landing position effects) for the critical distractors were almost the

5 mirror image of those for the target words. In contrast, the pattern of distractor skipping data was

6 more similar to normal reading despite increased skipping rates and attenuated word frequency

7 effects. Given that both the landing position data and the skipping data reflect oculomotor

8 control decisions regarding where to move the eyes in reading (i.e., which word to select as the

9 target of a saccade vs. where within a word to target a saccade), the effects obtained within the

10 selective reading paradigm suggest differential levels of flexibility in relation to these different

11 types of "where" decisions ${ }^{1}$. That is, it appears that whilst some aspects of "where" decision

12 making in reading are relatively pliable, others are more impervious to strategic control. At

13 present, current models of eye-movement control in reading do not provide a straightforward

14 explanation for this pattern of findings. Further research is required in order to explore the

15 behavioral and neurophysiological factors underpinning these different aspects of "where"

16 decision making.

17 The above findings concerning the processing of distractors raise several important issues.

18 Although readers displayed impressive efficiency in selectively ignoring distractors as compared

19 to target words, one may wonder why readers ever fixated the distractor strings at all. It is

20 clearly the case that saccadic targeting in selective reading is not perfect (otherwise readers

21 would never have fixated the distractor strings and skipping rates for these would be $100 \%$ ). To

22 put this issue in perspective, it is instructive to consider similar findings concerning saccadic

23 selectivity in visual search (see Reingold \& Glaholt, 2014, for a recent summary). Specifically, 
1 perfect saccadic selectivity based on color cues was similarly not obtained in visual search

2 studies (see Williams \& Reingold, 2001) despite the fact that such studies employed minimum

3 distances between adjacent display items that were much larger than the space between

4 distractors and targets in the present paradigm. In general terms, it is likely that some of the

5 fixations on distractors in the present study arose due to oculomotor noise. It is well documented

6 that saccadic targeting in reading is inherently noisy (e.g. McConkie, Kerr, Reddix, \& Zola,

7 1988), and therefore some saccades to distractors will simply reflect mislocated fixations

8 (Drieghe, Rayner, \& Pollatsek, 2008). The large increase in the proportion of outer fixations on

9 distractors relative to targets is consistent with this explanation (i.e., possibly indicating that

10 mislocated fixations constitute a substantial proportion of fixations on distractors). Furthermore,

11 normal reading involves the operation of highly practiced oculomotor routines. Readers make

12 very fast motoric responses in tight synchrony with complex visual and cognitive processes.

13 Importantly, the default action after every fixation during normal reading is to target the next

14 saccade to the upcoming word in the sentence. Usually a word is skipped when it is short,

15 predictable and/or high frequency. To be clear, skipping of words - although frequent - is the

16 exception rather than the norm. In contrast, in the selective reading paradigm, the default action

17 is to skip. That is to say, for perfect performance to occur in the current implementation of the

18 selective reading paradigm, readers must make a saccade to skip a word after each fixation. This

19 required action is in direct conflict with the default motoric response required in the overlearned

20 activity of normal reading. It is perhaps unsurprising, therefore, that readers often make

21 fixations on distractors when they are engaged in selective reading.

The above considerations notwithstanding, the proportion of fixations on distractors exceeds what we might reasonably anticipate as a consequence of oculomotor error. 
1 Furthermore, the fact that the nature of the distractors systematically influenced saccadic

2 targeting indicates that there are clearly other influential factors involved. In particular, despite

3 the fact that the color of a critical distractor categorically indicated that it was irrelevant to

4 sentence meaning, there remained differences in distractor skipping rates and first-pass fixation

5 durations as a function of Distractor type. Specifically, symbol distractors were much more

6 likely to be skipped or briefly fixated than word distractors. It is clear that parafoveal processing

7 of the color cue permitted the guidance of saccadic endpoints away from irrelevant distractors

8 and towards the relevant sentence words resulting in much higher skipping rates for the former

9 than the latter. It is possible that low level feature differences between symbol distractors and

10 normal text provided shape cues that in parallel to the processing of the color cues increased

11 saccadic selectivity for symbol distractors. According to this interpretation, greater saccadic

12 selectivity in the case of symbol distractors was due to simultaneous parafoveal processing of

13 both color and shape cues, while only the color cue was available to guide saccadic endpoints in

14 the case word distractors. In fact, such a pattern of saccadic selectivity due to simultaneous

15 guidance by color and shape in a visual search task was demonstrated by Williams and Reingold 16 (2001).

17 However, another non-mutually exclusive explanation of the processing differences

18 between symbol and word distractors is that the linguistically meaningful word distractors were

19 subjected to at least occasional orthographic and/or lexical processing. By this interpretation, it

20 seems likely that readers processed information about the visual form of the parafoveal string,

21 and if that string was word-like in appearance, then they had an increased tendency to fixate and

22 process it. Note also that this pattern of results occurred even though the color of the string

23 indicated categorically that the word was irrelevant to the meaning of the sentence. 
1 Consequently, even when words were irrelevant to the linguistic interpretation underway there

2 might have been an involuntarily tendency to fixate and process these words at least

3 occasionally. This suggestion is consistent with the numerical trend showing greater skipping

4 rates and shorter first-pass fixation durations for high frequency than low frequency distractor

5 words. These word frequency effects, although greatly attenuated compared to those obtained in

6 normal reading, provide some support for at least sporadic lexical processing of distractors.

7 In the final section of this paper we will consider the present findings in relation to models

8 of eye-movement control in reading. However, it is worth bearing in mind that the selective

9 reading paradigm requires participants to engage in reading behavior that may be quite different

10 than normal reading. Given this, it may be sensible to exhibit caution in using the present

11 findings to evaluate SAS and GAG models. Nevertheless, we would argue that some of the

12 findings obtained in the present experiments might be very informative with respect to eye-

13 movement control in reading. Consider, for example, the fact that in trials in which the distractor

14 was skipped, we observed robust preview benefits (i.e., shorter first-pass fixation durations on

15 the target in valid than invalid preview conditions). This finding provides very strong evidence

16 for parafoveal processing of the target word despite the intervening distractor which occupied the

17 space that under normal reading conditions would constitute word $N+1$. Such a preview benefit

18 is consistent with GAG models that predict word $N+2$ preview benefits should occur quite

19 generally due to concurrent processing of words within the attentional gradient. The effect we

20 obtained might also be consistent with SAS models such as the E-Z Reader model, if one

21 assumes that the salient color cue permitted covert attention to shift selectively, and thus largely

22 skip or only briefly pause on distractors. In such a situation, the target word would be processed

23 as the upcoming parafoveal word even in the presence of the intervening distractor string. 
Importantly, our findings of robust preview benefits in distractor-skipped trials is in

2 marked contrast to the fact that it has been difficult to obtain consistent demonstrations of word

$3 N+2$ preview benefits using a variant of the boundary paradigm (Rayner, Juhasz, \& Brown,

4 2007; see Radach \& Kennedy, 2013; Schotter et al., 2012 for reviews). Specifically, findings of

5 modest word $N+2$ preview benefits were reported under conditions in which word $N+1$ was very

6 short (three-letter) and high frequency (e.g., Kliegl, Risse, \& Laubrock, 2007; Radach, Inhoff,

7 Glover, \& Vorstius, 2013; Risse \& Kliegl, 2011). In contrast, Angele and Rayner (2011) did not

8 obtain word $N+2$ preview effects, even when word $N+1$ was the word "the". With Chinese text,

9 a word $N+2$ preview effect was obtained for a high frequency word $N+1$ (Yang, Wang, Xu, \&

10 Rayner, 2009) but not for a low frequency word N+1 (Yang, Rayner, Li, \& Wang, 2012).

11 Similarly, Yan, Kliegl, Shu, Pan and Zhou (2010) showed that the ease with which word $N+1$ is

12 processed modulates the effectiveness with which word $N+2$ is processed in Chinese reading.

13 Thus, the evidence for word $N+2$ preview effects is mixed with some studies providing evidence

14 for such effects, and other studies failing to obtain such evidence. It has been proposed that the

15 difficulty in obtaining clear evidence for word $N+2$ preview effects might be due to visual acuity

16 drop-off at higher eccentricities as well as by the limited size of the perceptual span (e.g., Radach

$17 \&$ Kennedy, 2013). However, the present findings are clearly inconsistent with such a proposal

18 (for a similar argument see Cutter, Drieghe, \& Liversedge, 2014). This illustrates one of the

19 promising aspects of the selective reading paradigm, namely, the ability to test the limits of

20 effective parafoveal processing by manipulating the number and/or length of irrelevant

21 distractors which are placed between adjacent words in the text while keeping the relevant

22 sentence unchanged. This would be an obvious extension of the present experiments that might

23 serve to provide critical information for models of eye-movement control in reading. 
With respect to the interpretation of the preview benefits that were obtained in either

2 distractor-skipped or distractor-fixated trials, it is important to consider the extent to which these

3 effects were modulated by distractor type. GAG models stipulate that a preview effect results

4 from an attentional gradient that in the selective reading paradigm would include both the critical

5 distractor and the target, and consequently the difficulty of processing the distractor should

6 modulate the magnitude of the preview benefit as they both compete for attentional resources

7 (i.e., greater difficulty of processing the critical distractor should result in a smaller preview

8 effect). In contrast, in line with an all-or-none attentional spotlight as per an SAS model such as

9 E-Z reader, no such modulation of the size of the preview benefit by distractor type should occur.

10 The evidence relating to these possibilities in the present experiments was mixed. Specifically,

11 given that it is clear that symbol distractors were processed to a far lesser degree than word

12 distractors, GAG models might predict a larger preview benefit in the former than the latter

13 condition. While such an effect was not obtained in terms of the pattern of preview effects on

14 first-pass fixation times on the target, target skipping rates were larger for symbol than word

15 distractors. Similarly, while there was no effect on the size of preview benefit as a function of

16 the word frequency of the critical distractor, target skipping rates showed a slight increase for

17 high frequency than low frequency distractors.

18 The strongest evidence that was obtained in the present experiments for simultaneous

19 processing of the critical distractor and the target occurred in a condition in which both were

20 identical (i.e., the repeated condition in Experiment 2). Specifically, the magnitude of the

21 preview benefit was larger when the critical distractor was identical to the target (repeated

22 condition) than when the distractor was a frequency-matched control word that was unrelated to

23 the target (control condition). This effect is reminiscent of a repetition effect observed by 
1 Angele, Tran, and Rayner (2012). In a boundary change experiment during reading, they

2 observed that the repetition of the foveal word in the parafovea (after the boundary) resulted in

3 shorter fixation durations on the foveal word and no evidence of additional disruption on the

4 parafoveal word when it was fixated after the boundary change. However, in their experiment,

5 processing the foveal word was relevant for the task, whereas in the current experiment the first

6 instance of the repetition was an irrelevant distractor. Note also that in the current experiment

7 the benefit of repetition occurred regardless of whether the distractor was fixated or skipped. It

8 appears that the commonality between the distractor and the target word resulted in facilitation

9 when the eyes moved to fixate the target, and this commonality exerted an influence even when

10 the distractor was processed solely in the parafovea. Importantly, however, when the pre-target

11 critical distractor was fixated, those fixations were uninfluenced by the identical target. If the

12 distractor and target were being processed completely in parallel, then we might have expected

13 facilitation in the form of shorter fixations for both the target (i.e., larger preview benefits) and

14 the distractor (i.e., parafoveal-on-foveal effects). While the former suggestion was clearly

15 supported by our findings there was no evidence consistent with the latter suggestion.

16 It seems likely that the increased preview benefit for the target word after an identical

17 distractor arose due to the distractor acting as a prime for the target. Within sentence

18 orthographic priming effects have been demonstrated to occur in alphabetic and non-alphabetic

19 languages across a number of experiments (Pagán, Paterson, Blythe, \& Liversedge, 2015;

20 Paterson, Alcock, \& Liversedge, 2011; Paterson, Liversedge, \& Davis, 2009; Wang, Tian, Han,

21 Liversedge, \& Paterson, 2014). In these experiments, orthographically related words appear in

22 the same sentence (e.g., There was a blur as the blue lights of the police car...) and effects of the

23 first word (blur) relative to a control word (gasp) are observed when readers fixate the second 
1 word (blue) downstream in the sentence (see also Frisson, Koole, Hughes, Olson \& Wheeldon,

2 2014, for a demonstration of the importance of phonological overlap for obtaining such priming

3 effects). Presumably, the effects we have observed in the present study are similar to these

4 effects reported earlier, except that the two words are identical rather than slightly different. If

5 this explanation is correct, then the effects observed at the target are likely to be

6 orthographically, phonologically and/or lexically based and to result from residual activation of

7 the target word by the identical distractor.

To summarize, considering the entire pattern of findings we obtained in the present

9 experiments, we are tentatively suggesting that the performance in the current implementation of

10 the selective reading paradigm represent a mixture of successes as well as failures on the part of

11 readers in their attempts to override highly practiced and arguably automatic perceptual,

12 cognitive and oculomotor aspects of normal reading. Specifically, the fact that readers were able

13 to quite effectively focus attention on the content words of sentences at the expense of distractor

14 words, and the striking pattern of differences in eye-movement parameters as a function of text

15 relevance, is consistent with the view that in addition to facilitating processing of the text within

16 the attended region, covert attention can also result in irrelevant distractor information being

17 suppressed during reading (at least in a reading paradigm that requires such suppression for

18 successful text comprehension). Such a role for covert attention in reading is consistent with the

19 findings that irrelevant text information on adjacent lines is not lexically processed (Inhoff \&

20 Briihl, 1991; Inhoff \& Topolski, 1994; Pollatsek et al., 1993; for a non-reading example of

21 distractor suppression see Cepeda et al., 1998; Gaspar \& McDonald, 2014; Moran \& Desimone,

22 1985). However, we also demonstrated that the suppression of distractors is not absolute and

23 despite the strong relevance cue that was provided (i.e., color), some differentiation (albeit rather 
1 shallow) as a function of Distractor type was evident. Although the implications of the present

2 findings for models of eye-movements control in reading must be considered with caution, we

3 would strongly argue that the present study illustrates the promise of the selective reading

4 paradigm as a potentially valuable tool for the study of the role of covert attention and eye-

5 movement control in reading. 


\section{References}

Angele, B., \& Rayner, K. (2011). Parafoveal processing of word $n+2$ during reading: do the preceding words matter? Journal of Experimental Psychology. Human Perception and Performance, 37(4), 1210-1220. http://doi.org/10.1037/a0023096

Angele, B., Tran, R., \& Rayner, K. (2012). Parafoveal-Foveal Overlap Can Facilitate Ongoing Word Identification During Reading: Evidence From Eye Movements. Journal of Experimental Psychology: Human Perception and Performance, 39(2), 526-538. http://doi.org/10.1037/a0029492

Bashinski, H. S., \& Bacharach, V. R. (1980). Enhancement of perceptual sensitivity as the result of selectively attending to spatial locations. Perception \& Psychophysics, 28(3), 241-248. http://doi.org/10.3758/BF03204380

Besner, D., Stolz, J. A., \& Boutilier, C. (1997). The stroop effect and the myth of automaticity. Psychonomic Bulletin \& Review, 4(2), 221-225. http://doi.org/10.3758/BF03209396

Brefczynski, J. A., \& DeYoe, E. A. (1999). A physiological correlate of the "spotlight" of visual attention. Nature Neuroscience, 2(4), 370-374. http://doi.org/10.1038/7280

Briand, K. A., \& Klein, R. M. (1987). Is Posner's "beam" the same as Treisman's "glue"?: On the relation between visual orienting and feature integration theory. Journal of Experimental Psychology. Human Perception and Performance, 13(2), 228-241. http://doi.org/10.1037/0096-1523.13.2.228

Brysbaert, M., Drieghe, D., \& Vitu, F. (2005). Word skipping: Implications for theories of eye movement control in reading. In G. Underwood (Ed.), Cognitive processes in eye guidance (pp. 53-77). Oxford: Oxford University Press.

Carrasco, M. (2011). Visual attention: The past 25 years. Vision Research, 51, 1484-1525.

Carrasco, M. (2014). Spatial covert attention: Perceptual modulation. In A. C. Nobre and S. Kastner (Eds.), The Oxford Handbook of Attention (pp. 183-230). Oxford: Oxford University Press.

Castiello, U., \& Umiltá, C. (1990). Size of the Attentional focus and efficiency of processing. Acta Psychologica, 73, 195-209.

Castiello, U., \& Umiltà, C. (1992). Splitting focal attention. Journal of Experimental Psychology. Human Perception and Performance, 18(3), 837-848. http://doi.org/10.1037/00961523.18.3.837 
Cepeda, N. J., Cave, K. R., Bichot, N. P., \& Kim, M. S. (1998). Spatial selection via featuredriven inhibition of distractor locations. Perception \& Psychophysics, 60(5), 727-746. http://doi.org/10.3758/BF03206059

Connor, C. E., Preddie, D. C., Gallant, J. L., \& Van Essen, D. C. (1997). Spatial attention effects in macaque area V4. The Journal of Neuroscience, 17(9), 3201-3214. Retrieved from papers2://publication/uuid/54DC78F1-F9B6-461F-9BB3-7EFBAA796B99

Cutter, M. G., Drieghe, D., \& Liversedge, S. P. (2014). Preview benefit in English spaced compounds. Journal of Experimental Psychology. Learning, Memory, and Cognition, 40(6), 1778-1786. http://doi.org/10.1037/xlm0000013

Deubel, H., \& Schneider, W. X. (1996). Saccade target selection and object recognition: Evidence for a common attentional mechanism. Vision Research, 36(12), 1827-1837. Retrieved from http://linkinghub.elsevier.com/retrieve/pii/0042698995002944

Downing, C. J. (1988). Expectancy and visual-spatial attention: effects on perceptual quality. Journal of Experimental Psychology. Human Perception and Performance, 14(2), 188-202. http://doi.org/10.1037/0096-1523.14.2.188

Downing, C. J., \& Pinker, S. (1985). The spatial structure of visual attention. In Attention and Performance (pp. 171-187). Hillsdale, N.J: Lawrence Erlbaum Associates.

Drieghe, D., Rayner, K., \& Pollatsek, A. (2008). Mislocated fixations can account for parafoveal-on-foveal effects in eye movements during reading. Quarterly Journal of Experimental Psychology, 61(8), 1239-1249. http://doi.org/10.1080/17470210701467953

Dunn-Rankin, P. (1978). The visual characteristics of words. Scientific American, 238, 122-130.

Engbert, R., Nuthmann, A., Richter, E. M., \& Kliegl, R. (2005). SWIFT: A dynamical model of saccade generation during reading. Psychological Review, 112(4), 777-813. http://doi.org/10.1037/0033-295X.112.4.777

Eriksen, C. W. (1990). Attentional search of the visual field. In D. Brogan (Ed.), Visual Search (pp. 3-19). London: Taylor Francis Ltd.

Eriksen, C. W., \& Murphy, T. D. (1987). Movement of attentional focus across the visual field: a critical look at the evidence. Perception \& Psychophysics, 42(3), 299-305. http://doi.org/10.3758/BF03203082

Eriksen, C. W., \& Schultz, D. (1977). Retinal locus and acuity in Visual Information Processing. Bulletin of the Psychonomic Society, 9(2), 81-84. http://doi.org/10.1097/00006324197710000-00030 
Eriksen, C. W., \& St James, J. D. (1986). Visual attention within and around the field of focal attention: a zoom lens model. Perception \& Psychophysics, 40(4), 225-240. http://doi.org/10.3758/BF03211502

Eriksen, C. W., \& Yeh, Y. Y. (1985). Allocation of attention in the visual field. Journal of Experimental Psychology Human Perception and Performance, 11(5), 583-597. http://doi.org/10.1037/0096-1523.11.5.583

Findlay, J. M., Brown, V., \& Gilchrist, I. D. (2001). Saccade target selection in visual search: The effect of information from the previous fixation. Vision Research, 41(1), 87-95. http://doi.org/10.1016/S0042-6989(00)00236-4

Findlay, J. M., \& Gilchrist, I. D. (1998). Eye Guidance and Visual Search. In G. Underwood (Ed.), Eye Guidance in Reading and Scene Perception (pp. 295-312). Elsevier.

Findlay, J. M., \& Walker, R. (1999). A model of saccade generation based on parallel processing and competitive inhibition. The Behavioral and Brain Sciences, 22(4), 661-74; discussion 674-721. Retrieved from http://www.ncbi.nlm.nih.gov/pubmed/11301526

Fodor, J. A. (1983). The modularity of mind. Cambridge, MA: MIT Press.

Frisson, S., Koole, H., Hughes, L., Olson, A., \& Wheeldon, L. (2014). Competition between orthographic and phonologically similar words during sentence reading: Evidence from eye movements. Journal of Memory and Language, 73, 148-173.

Gandhi, S. P., Heeger, D. J., \& Boynton, G. M. (1999). Spatial attention affects brain activity in human primary visual cortex. Proceedings of the National Academy of Sciences of the United States of America, 96(March), 3314-3319.

Gaspar, J. M., \& McDonald, J. J. (2014). Suppression of salient objects prevents distraction in visual search. The Journal of Neuroscience, 34(16), 5658-5666. http://doi.org/10.1523/JNEUROSCI.4161-13.2014

Henderson, J. M. (1992). Visual attention and eye movement control during reading and scene perception. In K. Rayner (Ed.), Eye movements and visual cognition (pp. 260-283). New York: Springer-Verlag.

Henderson, J. M. (1993). Visual attention and saccadic eye movements. In G. D'Ydewalle \& J. Van Rensbergen (Eds.), Perception and cognition: Advances in eye movement research (pp. 37-50). Amsterdam.

Henderson, J. M., \& Ferreira, F. (1990). Effects of foveal processing difficulty on the perceptual span in reading: implications for attention and eye movement control. Journal of Experimental Psychology. Learning, Memory, and Cognition, 16(3), 417-429. http://doi.org/10.1037/0278-7393.16.3.417 
Hoffman, J. E. (1998). Visual attention and eye movements. In H. Pashler (Ed.), Attention (pp. 119-153). London: University College London Press.

Hoffman, J. E., \& Subramaniam, B. (1995). The role of visual attention in saccadic eye movements. Perception \& Psychophysics, 57(6), 787-795. http://doi.org/10.3758/BF03206794

Hooge, I. T., \& Erkelens, C. J. (1999). Peripheral vision and oculomotor control during visual search. Vision Research, 39(8), 1567-1575. http://doi.org/10.1016/S0042-6989(98)00213-2

Ikeda, M., \& Saida, S. (1978). Span of recognition in reading. Vision Resaerch, 18, 83-88.

Inhoff, A. W., \& Briihl, D. (1991). Semantic processing of unattended text during selective reading: how the eyes see it. Perception \& Psychophysics, 49(3), 289-294.

http://doi.org/10.3758/BF03214312

Inhoff, A. W., \& Liu, W. (1998). The perceptual span and oculomotor activity during the reading of Chinese sentences. Journal of Experimental Psychology. Human Perception and Performance, 24(1), 20-34. http://doi.org/10.1037/0096-1523.24.1.20

Inhoff, A. W., Pollatsek, A., Posner, M. I., \& Rayner, K. (1989). Covert attention and eye movements during reading. The Quarterly Journal of Experimental Psychology. A: Human Experimental Psychology, 41A(1), 63-89. http://doi.org/10.1080/14640748908402353

Inhoff, A. W., \& Rayner, K. (1986). Parafoveal word processing during eye fixations in reading: Effects of word frequency. Perception \& Psychophysics, 40(6), 431-439.

Inhoff, A. W., \& Topolski, R. (1994). Use of phonological codes during eye fixations in reading and in on-line and delayed naming tasks. Journal of Memory and Language, 33, 689-713.

Ishihara, S. (1964). Tests for colour-blindness. (Kanehara Shuppan Co. Ltd, Ed.). Tokyo, Japan.

Ito, M., \& Gilbert, C. D. (1999). Attention modulates contextual influences in the primary visual cortex of alert monkeys. Neuron, 22(3), 593-604. http://doi.org/10.1016/S08966273(00)80713-8

Jonides, J. (1980). Towards a model of the mind's eye's movement. Canadian Journal of Psychology, 34(2), 103-112.

Just, M. A., \& Carpenter, P. A. (1980). A theory of reading: from eye fixations to comprehension. Psychological Review, 87(4), 329-354. http://doi.org/10.1037/0033295X.87.4.329

Kaakinen, J. K., \& Hyönä, J. (2014). Task relevance induces momentary changes in the functional visual field during reading. Psychological Science, 25(2), 626-32. http://doi.org/10.1177/0956797613512332 
Kastner, S., De Weerd, P., Desimone, R., \& Ungerleider, L. (1998). Mechanisms of directed attention in the human extrastriate cortex as revealed by functional MRI. Science, 282, 108 111.

Kennison, S. M., \& Clifton, C. (1995). Determinants of parafoveal preview benefit in high and low working memory capacity readers: implications for eye movement control. Journal of Experimental Psychology. Learning, Memory, and Cognition, 21(1), 68-81. http://doi.org/10.1037/0278-7393.21.1.68

Kliegl, R., Risse, S., \& Laubrock, J. (2007). Preview benefit and parafoveal-on-foveal effects from word $\mathrm{n}+2$. Journal of Experimental Psychology. Human Perception and Performance, 33(5), 1250-1255. http://doi.org/10.1037/0096-1523.33.5.1250

Kowler, E., Anderson, E., Dosher, B., \& Blaser, E. (1995). The role of attention in the programming of saccades. Vision Research, 35(13), 1897-1916.

http://doi.org/10.1016/0042-6989(94)00279-U

LaBerge, D., \& Brown, V. (1989). Theory of attentional operations in shape identification. Psychological Review, 96(1), 101-124. http://doi.org/10.1037/0033-295X.96.1.101

Liversedge, S. P., Drieghe, D., Li, X., Yan, G., Bai, X., \& Hyönä, J. (2016). Universality in eye movements and reading: A trilingual investigation. Cognition, 147, 1-20. http://doi.org/10.1016/j.cognition.2015.10.013

Luck, S. J., Chelazzi, L., Hillyard, S. a, \& Desimone, R. (1997). Neural mechanisms of spatial selective attention in areas V1, V2, and V4 of macaque visual cortex. Journal of Neurophysiology, 77(1), 24-42.

MacLeod, C. M. (1991). Half a century of research on the Stroop effect: An integrative review. Psychological Bulletin, 109(2), 163-203. http://doi.org/Doi 10.1037//0033-2909.109.2.163

Martínez, A., Anllo-Vento, L., Sereno, M. I., Frank, L. R., Buxton, R. B., Dubowitz, D. J., ... Hillyard, S. a. (1999). Involvement of striate and extrastriate visual cortical areas in spatial attention. Nature Neuroscience, 2(4), 364-369. http://doi.org/10.1038/7274

Matin, E. (1974). Saccadic suppression: A review and an analysis. Psychological Bulletin, 81(12), 899-917.

Mcadams, C. J., \& Maunsell, J. H. R. (2000). Attention to Both Space and Feature Modulates Neuronal Responses in Macaque Area V4. Journal of Neurophysiology, 83(3), 1751-1755.

McConkie, G. W., Kerr, P. W., Reddix, M. D., \& Zola, D. (1988). Eye movement control during reading: 1. The location of intial eye fixations on words. Vision Research, 28(10), 11071118 . 
McConkie, G. W., \& Rayner, K. (1975). The span of the effective stimulus during a fixation in reading. Perception \& Psychophysics, 17(6), 578-586. http://doi.org/10.3758/BF03203972

Miellet, S., O’Donnell, P. J., \& Sereno, S. C. (2009). Parafoveal Magnification: Visual acuity does not modulate perceptual span in reading. Psychological Science, 20(6), 721-728. http://doi.org/10.1111/j.1467-9280.2009.02364.x

Moran, J., \& Desimone, R. (1985). Selective Attention Gates Visual Processing in the Extrastriate Cortex. Science, 229, 782-784.

Morrison, R. E. (1984). Manipulation of stimulus onset delay in reading: evidence for parallel programming of saccades. Journal of Experimental Psychology. Human Perception and Performance, 10(5), 667-682. http://doi.org/10.1037/0096-1523.10.5.667

Müller, N. G., Donner, T. H., Bartelt, O. A., Brandt, S. A., Villringer, A., \& Kleinschmidt, A. (2003). The functional neuroanatomy of visual conjunction search: A parametric fMRI study. NeuroImage, 20(3), 1578-1590. http://doi.org/10.1016/S1053-8119(03)00416-6

Murray, W. S., Fischer, M. H., \& Tatler, B. W. (2013). Serial and parallel processes in eye movement control: current controversies and future directions. Quarterly Journal of Experimental Psychology, 66(3), 417-428. http://doi.org/10.1080/17470218.2012.759979

Nuthmann, A., Engbert, R., \& Kliegl, R. (2005). Mislocated fixations during reading and the inverted optimal viewing position effect. Vision Research, 45(17), 2201-2217. http://doi.org/10.1016/j.visres.2005.02.014

Nuthmann, A., Engbert, R., \& Kliegl, R. (2007). The IOVP effect in mindless reading: Experiment and modeling. Vision Research, 47(7), 990-1002. http://doi.org/10.1016/j.visres.2006.11.005

Pagán, A., Paterson, K. B., Blythe, H. I., \& Liversedge, S. P. (2015). An inhibitory influence of transposed-letter neighbors on eye movements during reading. Psychonomic Bulletin \& Review. http://doi.org/10.3758/s13423-015-0869-5

Paterson, K. B., Alcock, A., \& Liversedge, S. P. (2011). Morphological priming during reading: Evidence from eye movements. Language and Cognitive Processes, 26(4-6), 600-623. http://doi.org/10.1080/01690965.2010.485392

Paterson, K. B., Liversedge, S. P., \& Davis, C. J. (2009). Inhibitory neighbor priming effects in eye movements during reading. Psychonomic Bulletin \& Review, 16(1), 43-50. http://doi.org/10.3758/PBR.16.1.43

Pollatsek, A., Bolozky, S., Well, A. D., \& Rayner, K. (1981). Asymmetries in the perceptual span for Israeli readers. Brain and Language, 14(1), 174-180. http://doi.org/10.1016/0093934X(81)90073-0 
Pollatsek, A., Raney, G. E., Lagasse, L., \& Rayner, K. (1993). The use of information below fixation in reading and in visual search. Canadian Journal of Experimental Psychology, 47(2), 179-200. http://doi.org/10.1037/h0078824

Pollatsek, A., \& Rayner, K. (1990). Reading. In M. I. Posner (Ed.), Foundations of Cognitive Science. Cambridge, MA: MIT Press.

Pomplun, M., Reingold, E. M., \& Shen, J. (2001). Investigating the visual span in comparative search: The effects of task difficulty and divided attention. Cognition, 81(2), B57-B67. http://doi.org/10.1016/S0010-0277(01)00123-8

Pomplun, M., Reingold, E. M., \& Shen, J. (2003). Area activation: A computational model of saccadic selectivity in visual search. Cognitive Science, 27(2), 299-312. http://doi.org/10.1016/S0364-0213(03)00003-X

Posner, M. I., Snyder, C. R., \& Davidson, B. J. (1980). Attention and the detection of signals. Journal of Experimental Psychology: General, 109(2), 160-174. http://doi.org/10.1037/0096-3445.109.2.160

Radach, R., Inhoff, A. W., Glover, L., \& Vorstius, C. (2013). Contextual constraint and N + 2 preview effects in reading. Quarterly Journal of Experimental Psychology, 66(3), 619-633. http://doi.org/10.1080/17470218.2012.761256

Radach, R., \& Kennedy, A. (2013). Eye movements in reading: some theoretical context. Quarterly Journal of Experimental Psychology, 66(3), 429-52. http://doi.org/10.1080/17470218.2012.750676

Rafal, R. D., Calabresi, P. A., Brennan, C. W., \& Sciolto, T. K. (1989). Saccade preparation inhibits reorienting to recently attended locations. Journal of Experimental Psychology. Human Perception and Performance, 15(4), 673-685. http://doi.org/10.1037/00961523.15.4.673

Rayner, K. (1975). The perceptual span and peripheral cues in reading. Cognitive Psychology, 7 , 65-81.

Rayner, K. (1977). Visual attention in reading: Eye movements reflect cognitive processes. Memory \& Cognition, 4, 443-448.

Rayner, K. (1979). Eye guidance in reading: Fixation locations within words. Perception, 8, 2130. http://doi.org/10.1068/p080021

Rayner, K. (1998). Eye movements in reading and information processing: 20 years of research. Psychological Bulletin, 124(3), 372-422. http://doi.org/10.1037/0033-2909.124.3.372 
Rayner, K. (2009). Eye movements and attention in reading, scene perception, and visual search. Quarterly Journal of Experimental Psychology (Vol. 62).

http://doi.org/10.1080/17470210902816461

Rayner, K., \& Duffy, S. A. (1986). Lexical complexity and fixation times in reading: Effects of word frequency, verb complexity, and lexical ambiguity. Memory \& Cognition, 14(3), 191201. Retrieved from http://www.ncbi.nlm.nih.gov/pubmed/3736392

Rayner, K., Juhasz, B. J., \& Brown, S. J. (2007). Do readers obtain preview benefit from word N +2 ? A test of serial attention shift versus distributed lexical processing models of eye movement control in reading. Journal of Experimental Psychology. Human Perception and Performance, 33(1), 230-245. http://doi.org/10.1037/0096-1523.33.1.230

Rayner, K., McConkie, G. W., \& Ehrlich, S. (1978). Journal of Experimental Psychology: Human Perception and Performance. Journal of Experimental Psychology: Human Perception and Performance, 4(4).

Rayner, K., \& Pollatsek, A. (1989). The psychology of reading. New Jersey: Prentice Hall.

Rayner, K., Slattery, T. ., \& Bélanger, N. N. (2010). Eye movements, the perceptual span, and reading speed. Psychonomic Bulletin \& Review, 17(6), 834-839. http://doi.org/10.3758/PBR.17.6.834

Rayner, K., Well, D., Pollatsek, A., \& Bertera, J. H. (1982). The availability of useful information to the right of fixation in reading. Perception \& Psychophysics, 31(6), 537-550. http://doi.org/10.3758/BF03204186

Reichle, E. D. (2011). Serial attention models of reading. In S. P. Liversedge, I. D. Gilchrist, \& S. Everling (Eds.), Oxford Handbook on Eye Movements (pp. 767-786). Oxford, UK: Oxford University Press.

Reichle, E. D., Pollatsek, A., Fisher, D. L., \& Rayner, K. (1998). Toward a model of eye movement control in reading. Psychological Review, 105(1), 125-157. http://doi.org/10.1037/0033-295X.105.1.125

Reichle, E. D., Reineberg, A. E., \& Schooler, J. W. (2010). Eye movements during mindless reading. Psychological Science, 21(9), 1300-1310. http://doi.org/10.1177/0956797610378686

Reichle, E. D., \& Reingold, E. M. (2013). Neurophysiological constraints on the eye-mind link. Frontiers in Human Neuroscience, 7, 361.

Reilly, R., \& Radach, R. (2003). Foundations of an interactive activation model of eye movement control in reading. In J. Hyona, R. Radach, \& H. Deubel (Eds.), The Mind's Eyes: Cognitive and Applied Aspects of Eye Movements. Oxford: Elsevier Science. 
Reingold, E. M., \& Glaholt, M. G. (2014). Cognitive control of fixation duration in visual search: The role of extrafoveal processing. Visual Cognition, 22(3), 1-25.

http://doi.org/10.1080/13506285.2014.881443

Reingold, E. M., Reichle, E. D., Glaholt, M. G., \& Sheridan, H. (2012). Direct lexical control of eye movements in reading: Evidence from a survival analysis of fixation durations. Cognitive Psychology, 65(2), 177-206. http://doi.org/10.1016/j.cogpsych.2012.03.001

Reingold, E. M., Sheridan, H., \& Reichle, E. D. (2015). Direct lexical and nonlexical control of fixation duration in reading. In A. Pollatsek, \& R. Treiman (Eds.), The Oxford Handbook of Reading (pp. 261-276). Oxford University Press, Oxford, UK. http://doi.org/10.1093/oxfordhb/9780199324576.013.10

Reingold, E. M., \& Stampe, D. M. (2004). Saccadic inhibition in reading. Journal of Experimental Psychology. Human Perception and Performance, 30(1), 194-211. http://doi.org/10.1037/0096-1523.30.1.194

Remington, R. W. (1980). Attention and saccadic eye movements. Journal of Experimental Psychology. Human Perception and Performance, 6(4), 726-744. http://doi.org/http://dx.doi.org/10.1037/0096-1523.6.4.726

Rensink, R. A. (2002). Change detection. Annual Review of Psychology, 53, 245-277. $\mathrm{http} / / /$ doi.org/10.1146/annurev.psych.53.100901.135125

Reynolds, J. H., Chelazzi, L., \& Desimone, R. (1999). Competitive mechanisms subserve attention in macaque areas V2 and V4. The Journal of Neuroscience, 19(5), 1736-1753.

Risse, S., \& Kliegl, R. (2011). Adult age differences in the perceptual span during reading. Psychology and Aging, 26(2), 451-460. http://doi.org/10.1037/a0021616

Schad, D. J., \& Engbert, R. (2012). The zoom lens of attention: Simulating shuffled versus normal text reading using the SWIFT model. Visual Cognition, 20(4-5), 391-421. doi:10.1080/13506285.2012.670143

Schad, D. J., Nuthmann, A., \& Engbert, R. (2012). Your mind wanders weakly, your mind wanders deeply: Objective measures reveal mindless reading at different levels. Cognition, 125(2), 179-194. http://doi.org/10.1016/j.cognition.2012.07.004

Schneider, W. X., \& Deubel, H. (1995). Visual attention and saccadic eye movements: Evidence for obligatory and selective spatial coupling. In J. M. Findlay, R. W. Kentridge, \& R. Walker (Eds.), Eye Movement Research: Mechanisms, Processes and Applications. (pp. 317-324). Amsterdam: Elsevier Science.

Schotter, E. R., Angele, B., \& Rayner, K. (2012). Parafoveal processing in reading. Attention, Perception, \& Psychophysics, 74(1), 5-35. http://doi.org/10.3758/s13414-011-0219-2 
Scialfa, C. T., \& Joffe, K. M. (1998). Response times and eye movements in feature and conjunction search as a function of target eccentricity. Perception \& Psychophysics, 60(6), 1067-1082. http://doi.org/10.3758/BF03211940

Shen, J., Reingold, E. M., \& Pomplun, M. (2000). Distractor ratio influences patterns of eye movements during visual search. Perception, 29(2), 241-250. http://doi.org/10.1068/p2933

Shepherd, M., Findlay, J. M., \& Hockey, R. J. (1986). The relationship between eye movements and spatial attention. The Quarterly Journal of Experimental Psychology. A, Human Experimental Psychology, 38(3), 475-491. http://doi.org/10.1080/14640748608401609

Shulman, G. L., Sullivan, M. ., Gish, K., \& Skaoda, W. J. (1986). The role of spatial-frequency channels in the perception of local and global structure. Perception, 15(3), 259-273.

Shulman, G. L., \& Wilson, J. (1987). Spatial frequency and selective attention to local and global information. Perception, 16(1), 89-101.

Shulman, G. L., Wilson, J., \& Sheehy, J. B. (1985). Spatial determinants of the distribution of attention. Perception \& Psychophysics, 37(1), 59-65. http://doi.org/10.3758/BF03207139

Simons, D. J. (2000). Current Approaches to Change Blindness. Visual Cognition, 7(1-3), 1-15. http://doi.org/10.1080/135062800394658

Somers, D. C., Dale, A. M., Seiffert, A. E., \& Tootell, R. B. (1999). Functional MRI reveals spatially specific attentional modulation in human primary visual cortex. Proceedings of the National Academy of Sciences of the United States of America, 96(4), 1663-1668. http://doi.org/10.1073/pnas.96.4.1663

Stroop, J. R. (1935). Studies of interference in serial verbal reactions. Journal of Experimental Psychology, 18(6), 643-662. http://doi.org/10.1037/h0054651

Tootell, R. B. ., Hadjikhani, N. K., Mendola, J. D., Marrett, S., \& Dale, A. M. (1998). From retinotopy to recognition: fMRI in human visual cortex. Trends in Cognitive Sciences, 2(5), 174-183.

Treue, S. (2004). Perceptual enhancement of contrast by attention. Trends in Cognitive Sciences, $8(10), 435-437$.

Treue, S., \& Maunsell, J. H. R. (1999). Effects of Attention on the Processing of Motion in Macaque Middle Temporal and Medial Superior Temporal Visual Cortical Areas. Jornal of Neuroscience, 19(17), 7591-7602.

Van Heuven, W. J. B., Mandera, P., Keuleers, E., \& Brysbaert, M. (2014). SUBTLEX-UK: A new and improved word frequency database for British English. Quarterly Journal of Experimental Psychology., 67(6), 1176-1190. http://doi.org/10.1080/17470218.2013.850521 
Vitu, F., Lancelin, D., \& Marrier d'Unienville, V. (2007). A perceptual-economy account for the inverted-optimal viewing position effect. Journal of Experimental Psychology: Human Perception and Performance, 33(5), 1220-1249. http://doi.org/10.1037/00961523.33.5.1220

Vitu, F., McConkie, G. W., Kerr, P., \& O’Regan, J. K. (2001). Fixation location effects on fixation durations during reading: An inverted optimal viewing position effect. Vision Research, 41, 3513-3533. http://doi.org/10.1016/S0042-6989(01)00166-3

Vitu, F., O’Regan, J. K., \& Mittau, M. (1990). Optimal landing position in reading isolated words and continuous text. Perception \& Psychophysics, 47(6), 583-600. http://doi.org/10.3758/BF03203111

Wang, J., Tian, J., Han, W., Liversedge, S. P., \& Paterson, K. B. (2014). Inhibitory stroke neighbour priming in character recognition and reading in Chinese. The Quarterly Journal of Experimental Psychology, 67(0), 37-41. http://doi.org/10.1080/17470218.2014.909507

Williams, D. E., \& Reingold, E. M. (2001). Preattentive guidance of eye movements during triple conjunction search tasks: the effects of feature discriminability and saccadic amplitude. Psychonomic Bulletin \& Review, 8(3), 476-488.

http://doi.org/10.3758/BF03196182

Yan, M., Kliegl, R., Shu, H., Pan, J., \& Zhou, X. (2010). Parafoveal load of word n+1 modulates preprocessing of word $\mathrm{n}+2$. Journal of Experimental Psychology: Human Perception and Performance, 36(6), 1669-1676. doi: 10.1037/a0019329

Yang, J., Rayner, K., Li, N., \& Wang, S. (2012). Is preview benefit from word $\mathrm{n}+2$ a common effect in reading Chinese? Evidence from eye movements. Reading and Writing, 25(5), 1079-1091. http://doi.org/10.1007/s11145-010-9282-7

Yang, J., Wang, S., Xu, Y., \& Rayner, K. (2009). Do Chinese readers obtain preview benefit from word $\mathrm{n}+2$ ? Evidence from eye movements. Journal of Experimental Psychology: Human Perception and Performance, 35(4), 1192-1204. http://doi.org/10.1037/a0013554

Zelinsky, G. J. (2008). A theory of eye movements during target acquisition. Psychological Review, 115(4), 787-835. http://doi.org/10.1037/a0013118 


\section{Footnotes}

${ }^{1} \mathrm{We}$ are indebted to Jane Ashby for pointing out this important implication of our data. 


\section{Acknowledgments}

This research was supported by an NSERC grant to Eyal Reingold. Correspondence concerning this paper should be sent to Eyal Reingold (reingold@psych.utoronto.ca). The authors are grateful to Monica Castelhano, Jane Ashby and Reinhold Kliegl for their helpful comments on a previous version of this manuscript. 


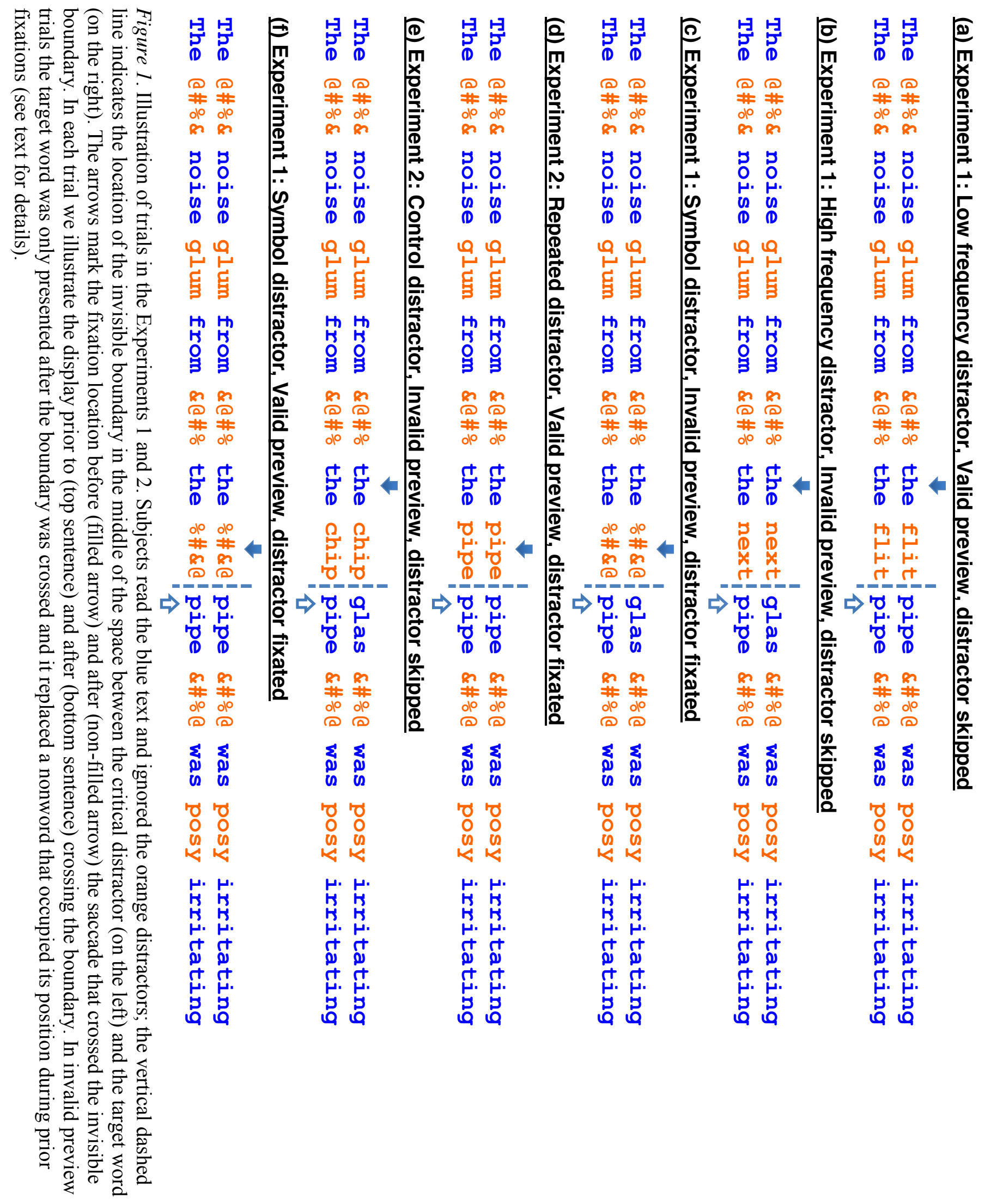



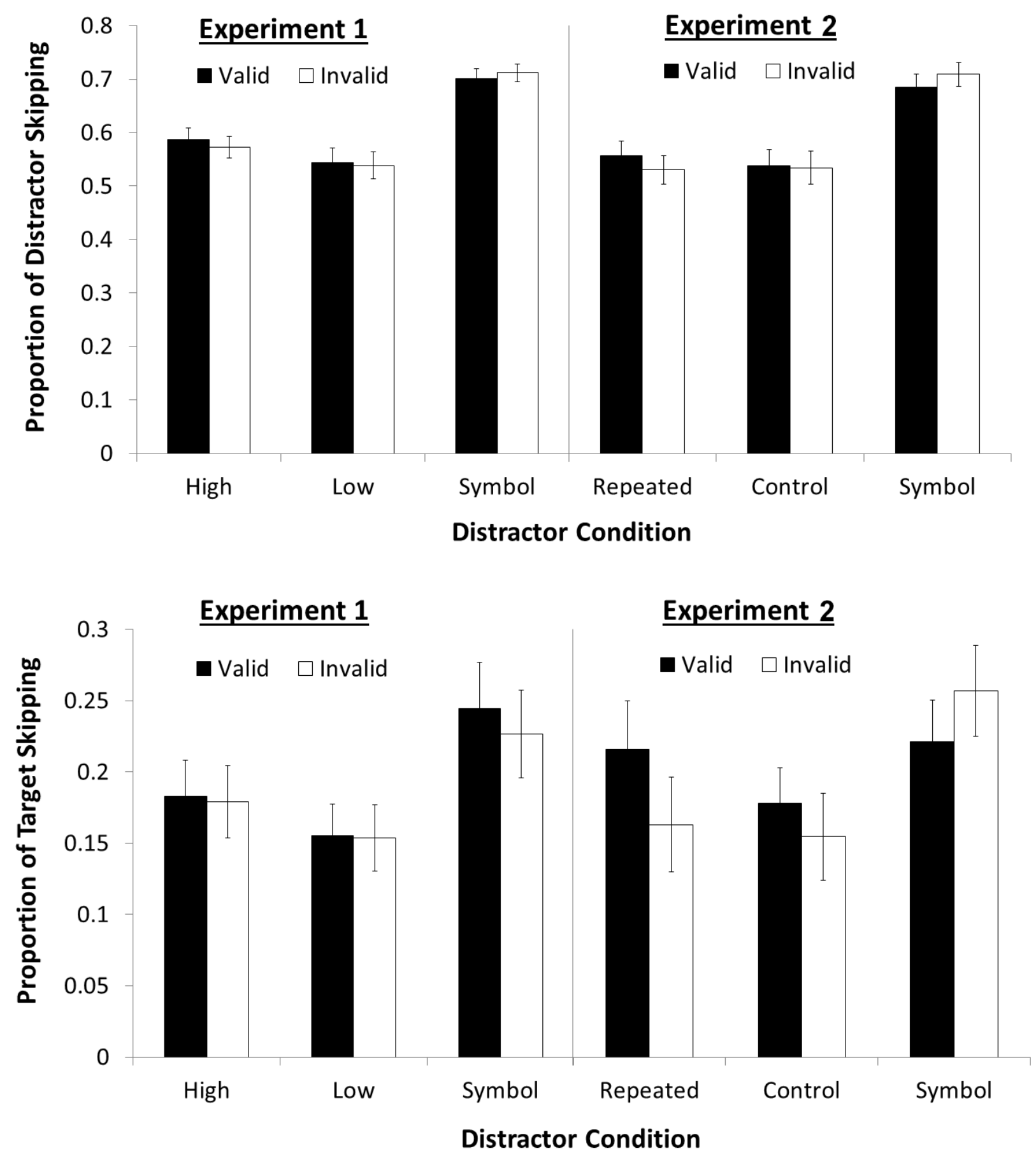

Figure 2. The proportion of critical distractor skipping (top panel) and the proportion of target word skipping (bottom panel) by Preview validity and Distractor type in Experiments 1 and 2. 

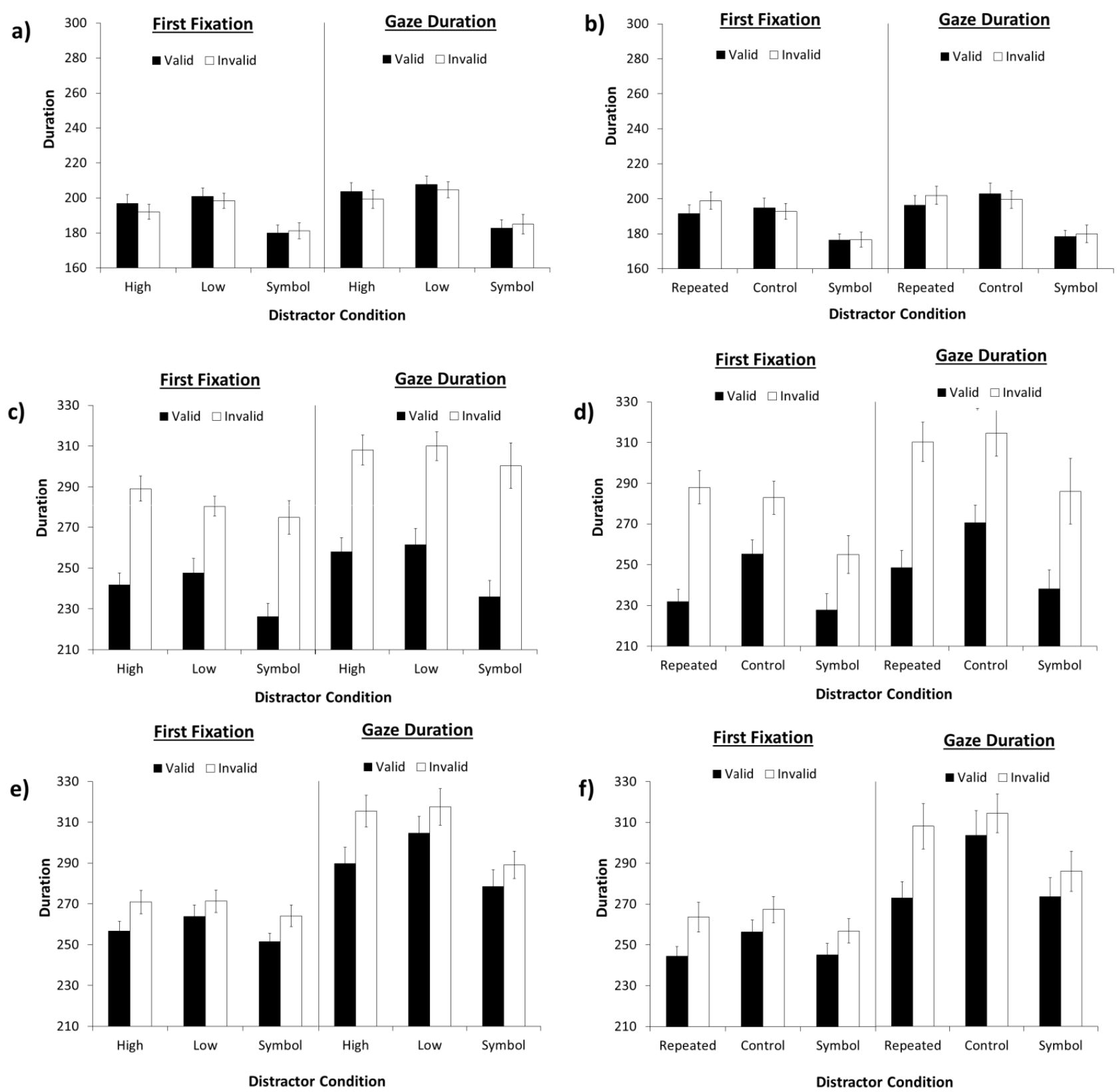

Figure 3. First-fixation duration and gaze duration by Preview validity and Distractor type in Experiment 1 (left column: Panels a, c, and e) and Experiment 2 (right column: Panels b, d, and f). The top row (Panels ab) shows first-pass fixation duration on the critical distractor. The middle row (Panels c-d) shows first-pass fixation duration on the target word in distractor-fixated trials. The bottom row (Panels e-f) shows first-pass fixation duration on the target word in distractor-skipped trials (see text for details) 


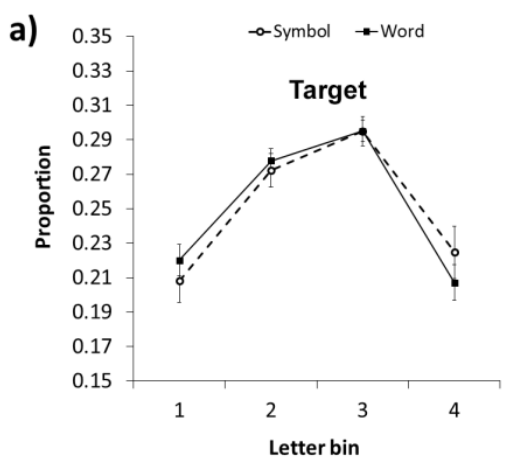

c)

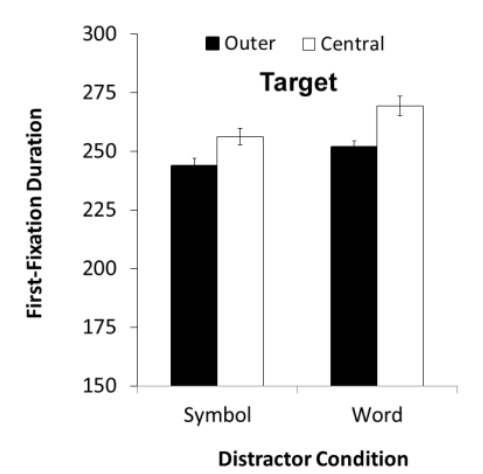

e)

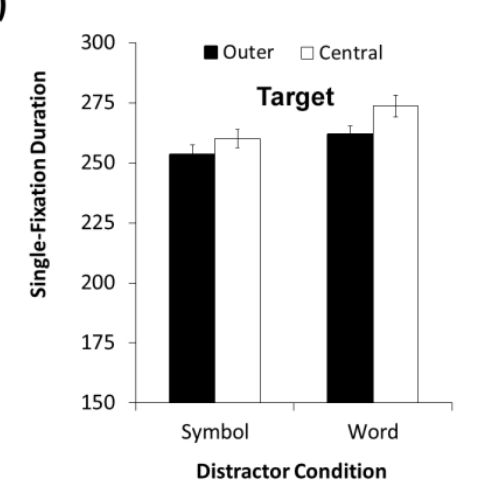

g)

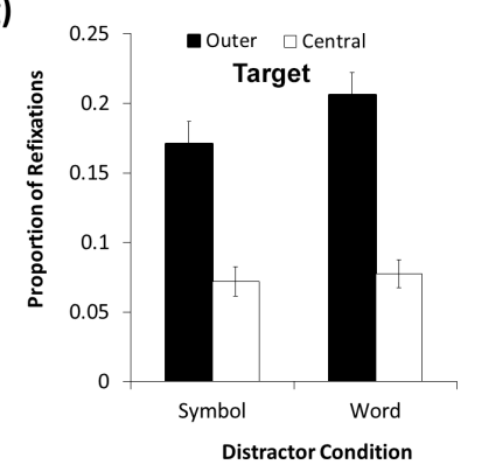

b)

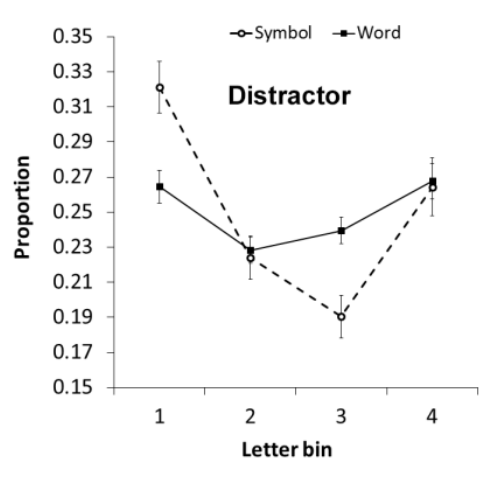

d)

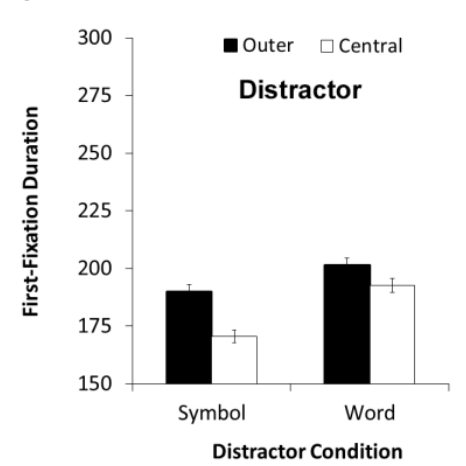

f)

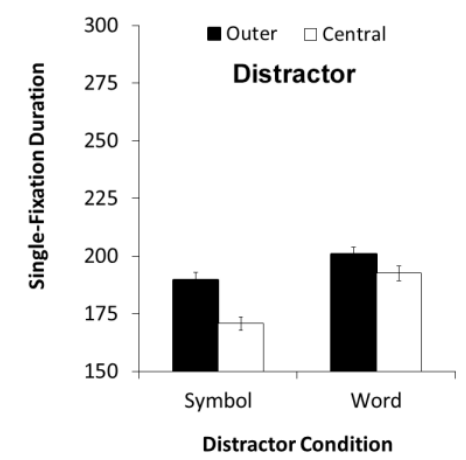

h)

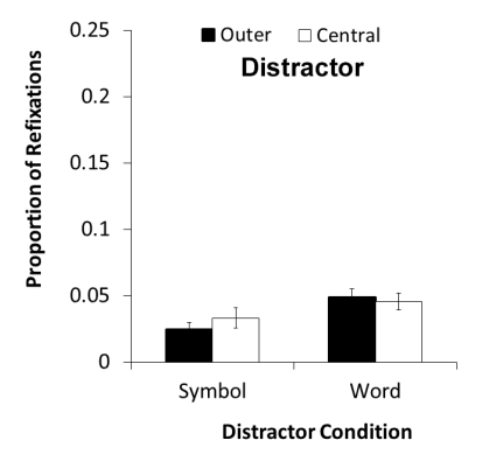

Figure 4. The distribution of the initial fixation location by Distractor type (symbol vs. word) on the target word (Panel a) and on the critical distractor (Panel b) and first-fixation duration (word: Panel c, distractor: Panel d), single fixation duration (word: Panel e, distractor: Panel f), and proportion of refixations (word: Panel g, distractor: Panel h) by Location (central vs. outer) and Distractor type (see text for details). 